\title{
The Spectral Dimension of Modeled Relative Humidity Feedbacks in the CMIP5 Experiments
}

\author{
FANG PAN \\ NASA Langley Research Center, Hampton, Virginia \\ Xianglei HuANG \\ Department of Climate and Space Sciences and Engineering, the University of Michigan at Ann Arbor, Ann Arbor, Michigan
}

(Manuscript received 24 July 2017, in final form 6 September 2018)

\begin{abstract}
The spectral radiative kernel technique is used to derive spectrally resolved relative humidity (RH) feedbacks for 16 GCMs that participated in CMIP5. Examining spectral and spatial details of these RH feedbacks leads to three findings. First, while the global average of broadband RH feedbacks is close to zero for all the GCMs, there exist wide discrepancies in the spectral details among the GCMs. Second, the spatial pattern of the RH feedbacks varies with spectral frequency; for a given frequency, the spatial feedback pattern correlates well with the spatial pattern of RH changes over the vertical layer to which the top-ofatmosphere spectral flux at the same frequency is most sensitive. Third, the nearly zero global average of broadband RH feedback is a result of spatial compensation and spectral compensation. Since GCMs have produced consistent RH feedbacks and RH changes to a large extent in the high latitudes, the tropical Atlantic, and the deep tropical Pacific, radiative RH kernels are further used to infer mean changes in $\mathrm{RH}$ vertical profiles from spectral RH feedbacks averaged over the three broad regions. Good agreements are demonstrated by comparing such inferences against the actual RH changes in the GCMs. This study suggests that the spectral dimension of RH feedback could provide an additional constraint to climate models and the understanding of vertical features of $\mathrm{RH}$ changes when they are obtainable from future observations.
\end{abstract}

\section{Introduction}

It is widely known that relative humidity $(\mathrm{RH})$ changes little in the global warming scenario simulated by GCMs (Ingram 2002; Allen and Ingram 2002; Pierrehumbert et al. 2007). Both climate models and observations indicate that global mean specific humidity in the atmosphere will increase with global mean surface temperature by $7 \% \mathrm{~K}^{-1}$, leading to "constant $\mathrm{RH}^{\prime}$ " in response to surface warming as implied by the ClausiusClapeyron relation (Wentz and Schabel 2000; Wentz et al. 2007; Trenberth et al. 2005). Additionally, water vapor feedbacks using specific humidity as a state variable in GCMs are also consistent with results that hold RH fixed (Colman and McAvaney 1997; Held and Soden 2000; Soden and Held 2006; Sherwood et al. 2010). Because of the tight coupling of temperature and water vapor changes in models, Held and Shell (2012) found out that it is physically logical to combine lapse-rate feedback

\footnotetext{
Corresponding author: Dr. Fang Pan, fangpan@umich.edu
}

and water vapor feedback together and to use $\mathrm{RH}$ as a state variable (hereafter referred to as the RH framework) instead of specific humidity. Thus they proposed $\mathrm{RH}$ feedback and calculated RH feedback as well as Planck and lapse-rate feedbacks under the RH framework for 18 models of phase 3 of the Coupled Model Intercomparison Project (CMIP3). These RH feedbacks are all close to zero with much smaller intermodel spread than that for the traditional water vapor feedback (using specific humidity as the state variable). The RH framework also removes most of the cancellation between traditional water vapor feedback and lapserate feedback, resulting in little correlation between RH feedback and lapse-rate feedback across the models. Caldwell et al. (2016) confirmed the same benefit of the RH framework when inspecting sources of model spreads for the estimated climate sensitivity. They found that the RH framework can reduce covariance between water vapor and lapse-rate feedbacks, covariance between water vapor and longwave cloud feedbacks, and the intermodel variance in these terms, making it easier 
to understand the feedback mechanisms than the conventional approach using specific humidity as a state variable.

Since last decade, the radiative kernel method has become a popular approach to compute radiative feedbacks from GCM archives. This method was pioneered by Soden and Held (2006), Soden et al. (2008), and Shell et al. (2008). The radiative kernel is the response of top of atmosphere (TOA) broadband flux to a unit perturbation in a given state variable. The radiative feedback for the state variable can then be estimated from the product of the radiative kernel and the change in this variable between two climate states. Traditionally, these radiative feedbacks are studied in terms of broadband flux, but intrinsically the TOA broadband flux is an integration of the spectral flux. Spectral decomposition of the TOA broadband flux has been proven useful in model diagnostics. For example, Huang et al. (2006) and Huang et al. (2007) revealed the compensating biases among spectral bands for the simulated outgoing longwave radiation (OLR). Huang and Ramaswamy (2008) demonstrated that spectral decomposition is useful to help assess the relationship between OLR and sea surface temperature, as well as the impact of water vapor on such relationships. Harries et al. (2001) and Brindley and Bantges (2016) showed how changes in climate variables are manifested across the spectrum and illustrated the advantage of spectral resolution over broadband radiation in the discriminatory power. The spectral dimension of radiative feedbacks can also provide additional insights for understanding feedbacks across the models. Huang et al. (2014) extended the use of radiative kernel approach from broadband to the spectral dimension, and developed and validated a set of longwave spectral radiative kernels. They showed that the broadband feedbacks derived from the spectral radiative kernels are highly consistent with those derived from widely used broadband kernels such as Soden et al. (2008) and Shell et al. (2008). They further showed that the lapse-rate and water vapor feedbacks from different GCMs can have different spectral dependences. To highlight the advantage of spectral diagnostics of the feedbacks, they showed a specific example with two GCMs having identical broadband lapse-rate feedback strength, but the spectral decompositions of the lapse-rate feedbacks from the two models are very different (Fig. S3 in Huang et al. 2014).

Motivated by the potentials of the RH framework in climate feedback studies and useful information contained in the spectral decomposition of broadband feedbacks, in this study we calculate the spectral RH feedbacks for 16 GCMs that participated in CMIP5
(Taylor et al. 2012). Then, based on these spectrally resolved RH feedbacks, a few questions we want to investigate are the following:

1) Although the global average of broadband $\mathrm{RH}$ feedbacks in all GCMs is close to zero, does such consistency remain throughout the longwave spectrum after spectral decomposition?

2) What is the spatial distribution of the RH feedbacks? How does the spatial pattern of RH feedbacks vary from one spectral band to another?

3) Over a large climate domain, can spectral decomposition of averaged broadband $\mathrm{RH}$ feedbacks qualitatively and quantitatively reveal useful information about actual RH changes at different pressure levels?

Bearing these questions in mind, we will examine the spatial and spectral details of the RH feedbacks in 16 GCMs and employ inversion techniques to quantitatively relate the vertical profiles of the $\mathrm{RH}$ changes with the spectrally resolved $\mathrm{RH}$ feedbacks. The rest of this paper is arranged as follows. Section 2 explains the method to calculate the spectral RH feedbacks in 16 GCMs. The spectral and spatial features of RH feedbacks as well as their consistency with actual RH changes are examined in section 3. Section 3 also discusses the relationship between regional spectral $\mathrm{RH}$ feedbacks and actual profiles of $\mathrm{RH}$ change in several regions. Conclusions and further discussion are presented in section 4.

\section{Data and method}

\section{a. Calculation of spectral $R H$ feedback}

We follow Held and Shell (2012) to replace specific humidity with $\mathrm{RH}$ as the state variable to compute radiative feedbacks. Held and Shell (2012) split traditional water vapor feedback $\lambda_{Q}$ (using specific humidity as the state variable) into three parts:

$$
\lambda_{Q}=\lambda_{Q_{\mid T}}+\lambda_{Q_{\mid L}}+\lambda_{\mathrm{RH}} \cdot
$$

The first three terms in Eq. (1) are the TOA flux response to a certain amount of humidity perturbation, divided by the global average surface temperature change. In the first term of Eq. (1), the TOA flux responds to the total specific humidity perturbation in the troposphere. In the second term the TOA flux responds to the specific humidity perturbation required by fixing $\mathrm{RH}$ while the tropospheric temperature perturbation is uniformly equal to the local surface temperature change. In the third term the TOA flux responds to the specific humidity perturbation required by fixing $\mathrm{RH}$ while tropospheric 
temperature is perturbed by its difference from the local change of surface temperature. The last term, the $\mathrm{RH}$ feedback $\lambda_{\mathrm{RH}}$ we are interested in, is the TOA spectral flux response to the change in RH divided by the global average surface temperature change.

To obtain $\lambda_{\mathrm{RH}}$, first we need to calculate $\lambda_{Q}, \lambda_{Q_{\mid T}}$, and $\lambda_{Q_{\mid}}$and then subtract $\lambda_{Q_{\mid T}}$ and $\lambda_{Q_{\left.\right|_{L}}}$ from $\lambda_{Q} ; \lambda_{Q}, \lambda_{Q_{\mid T}}$, and $\lambda_{Q_{\mid}}$are calculated by the spectral radiative kernel approach in Huang et al. (2014). Specifically, the TOA spectral flux change $\Delta R$ at a given frequency $\nu$ in response to a state variable change $\Delta x$ on a grid box (lat, lon) at a given time $t$ caused by the increase of surface temperature can be approximated as

$$
\begin{aligned}
\Delta R(\text { lat }, \text { lon }, \nu ; t) & \approx \sum_{p=1}^{N} \frac{\partial R(\text { lat }, \text { lon }, \nu, t)}{\partial x(\text { lat }, \text { lon }, p, t)} \Delta x(\text { lat }, \text { lon }, p, t) \\
& =\mathbf{K} \cdot \Delta \mathbf{X},
\end{aligned}
$$

where the term $\mathbf{K}$ or $\partial R / \partial x$ denotes the spectral radiative feedback kernel (hereafter we refer to the kernel as $\mathbf{K}$ for brevity) for a state variable $x(p)$ (e.g., temperature or logarithm of specific humidity at the $p$ th level, and $N$ is the total number of tropospheric levels). After calculating $\Delta R$ due to the change in certain state variable $x$, the climate feedback $\lambda_{x}$ can be derived as

$$
\lambda_{x}=\Delta R\left(\Delta T_{\text {surf }}\right)^{-1},
$$

where $\Delta T_{\text {surf }}$ is the global mean surface temperature change. Details about how to construct and validate the spectral radiative kernels can be found in Huang et al. (2014). Specifically, one year of 3-hourly profiles of temperature, specific humidity, cloud fraction, cloud liquid, and ice water content as simulated by the GFDL AM2 model (Anderson et al. 2004) were fed into the principal component-based radiative transfer model (PCRTM; Liu et al. 2006; Chen et al. 2013) to simultaneously compute longwave spectral radiative kernels for temperature and specific humidity at intervals of $10 \mathrm{~cm}^{-1}$.

The kernel for specific humidity considers the TOA spectral flux response to the change of logarithm of specific humidity (i.e., the fractional change in humidity). For this study, we multiply the set of spectral radiative kernels derived in Huang et al. (2014) by atmospheric state perturbations and divide the results by the global average surface temperature change to obtain spectrally resolved $\lambda_{Q}, \lambda_{Q_{\mid T}}$, and $\lambda_{Q_{L}}$. The atmospheric state perturbations are changes of monthly output from years $1-20$ to years $61-80$ in an 80 -yr simulation with a $1 \% \mathrm{CO}_{2}$ increase per year from $16 \mathrm{GCMs}$ that participated in the CMIP5 (Taylor et al. 2012). Information about the 16 GCMs can be found in Table 1. After longwave spectral feedbacks $\lambda_{Q_{\mid T}}, \lambda_{Q_{\mid L}}$, and $\lambda_{Q}$ are computed, we subtract $\lambda_{Q_{\mid T}}$ and $\lambda_{Q_{\mid L}}$ from $\lambda_{Q}$ to obtain the spectral RH feedback $\lambda_{\mathrm{RH}}$.

\section{b. Spectral $R H$ radiative kernel}

The spectral radiative kernel for $\mathrm{RH}$ can be shown to be approximately equivalent to the spectral kernel for specific humidity as follows. From Eqs. (1)-(3), on a one grid box we can obtain

$$
\begin{aligned}
\Delta R_{\mathrm{RH}}= & K_{\log (Q)} \Delta \log (Q)-K_{\log (Q)} \Delta \log \left(Q_{\mid T}\right) \\
& -K_{\log (Q)} \Delta \log \left(Q_{\mid L}\right) .
\end{aligned}
$$

On the right side, $K_{\log (Q)}$ is the spectral radiative kernel for the logarithm of specific humidity. The meanings of $Q, Q_{\mid T}, Q_{\mid L}$, and RH are the same as for Eq. (1). Also, $\Delta \log (Q)$ is the total specific humidity change between two climate states; $\Delta \log \left(Q_{\mid T}\right)$ is the specific humidity change to hold $\mathrm{RH}$ fixed when temperature at each level increases by local surface temperature change; and $\Delta \log \left(Q_{\mid L}\right)$ is the specific humidity change to hold $\mathrm{RH}$ fixed when temperature at each level changes by its difference from the local surface temperature change. Specifically, in this paper regarding humidity perturbation we only consider its fractional change (i.e., the change of logarithm of specific humidity or relative humidity). The term $\Delta R_{\mathrm{RH}}$ is the spectral flux change responding to RH change between the two climate states. The RH change, if in logarithmic scaling, is

$$
\Delta \log (\mathrm{RH})=\Delta \log (Q)-\Delta \log \left(Q_{s}\right) .
$$

The term $\Delta \log \left(Q_{s}\right)$ is the change in saturated specific humidity and derived as the function of temperature change $\Delta T$ according to the Clausius-Clapeyron relation:

$$
\Delta \log \left(Q_{s}\right)=\frac{L}{R_{v} T^{2}} \Delta T,
$$

where $L$ is specific latent heat and $R_{v}$ is the gas constant. From Eq. (6) and the definitions of $\Delta \log \left(Q_{\mid T}\right)$ and $\Delta \log \left(Q_{\mid L}\right)$, we can get

$$
\begin{aligned}
\Delta \log \left(Q_{\mid T}\right) & =\frac{L}{R_{v v} T^{2}} \Delta T_{\text {surf }}^{*}, \\
\Delta \log \left(Q_{\mid L}\right) & =\frac{L}{R_{v} T^{2}}\left(\Delta T-\Delta T_{\text {surf }}^{*}\right), \quad \text { and } \\
\Delta \log \left(Q_{s}\right) & =\Delta \log \left(Q_{\mid T}\right)+\Delta \log \left(Q_{\mid L}\right) .
\end{aligned}
$$

Here $\Delta T_{\text {surf }}^{*}$ in Eqs. (7) and (8) is the surface temperature change on this individual grid box. Finally combining 
TABLE 1. Summary of the 16 GCMs in CMIP5.

\begin{tabular}{ll}
\hline \multicolumn{1}{c}{ Model name and resolution } & \multicolumn{1}{c}{ Modeling center } \\
\hline BCC_CSM1.1 $\left(\sim 2.8^{\circ} \times 2.8^{\circ}\right)$ & Beijing Climate Center, China Meteorological Administration \\
BNU-ESM $\left(\sim 2.8^{\circ} \times 2.8^{\circ}\right)$ & Beijing Normal University \\
CanESM2 $\left(\sim 2.8^{\circ} \times 2.8^{\circ}\right)$ & Canadian Centre for Climate Modeling and Analysis \\
CCSM4 $\left(0.9^{\circ} \times 1.25^{\circ}\right)$ & National Center for Atmospheric Research \\
CESM1 $(C A M 5)\left(0.9^{\circ} \times 1.25^{\circ}\right)$ & National Center for Atmospheric Research \\
CNRM-CM5 $\left(\sim 1.4^{\circ} \times 1.4^{\circ}\right)$ & Centre National de Recherches Meteorologiques \\
GFDL CM3 $\left(2^{\circ} \times 2.5^{\circ}\right)$ & NOAA Geophysical Fluid Dynamics Laboratory \\
GISS-E2-H $\left(2^{\circ} \times 2.5^{\circ}\right)$ & NASA/GISS \\
GISS-ES-R $\left(2^{\circ} \times 2.5^{\circ}\right)$ & NASA/GISS \\
HadGEM2-ES $\left(\sim 1.3^{\circ} \times 1.9^{\circ}\right)$ & Met Office Hadley Centre \\
INM-CM4.0 $\left(1.5^{\circ} \times 2^{\circ}\right)$ & Russian Institute for Numerical Mathematics \\
IPSL-CM5A-LR $\left(1.9^{\circ} \times 3.75^{\circ}\right)$ & Institute Pierre-Simon Laplace \\
MIROC5 $\left(1.4^{\circ} \times 1.4^{\circ}\right)$ & Atmosphere and Ocean Research Institute (The University of Tokyo), National Institute for \\
& Environmental Studies, and Japan Agency for Marine-Earth Science and Technology \\
MPI-ESM-LR $\left(1.875^{\circ} \times 1.875^{\circ}\right)$ & Max Planck Institute for Meteorology \\
MRI-CGCM3 $\left(1.125^{\circ} \times 1.125^{\circ}\right)$ & Meteorological Research Institute \\
NorESM1-M $\left(1.9^{\circ} \times 0.5^{\circ}\right)$ & Norwegian Climate Centre \\
\hline
\end{tabular}

Eqs. (4), (5), and (9), the spectral flux change responding to $\mathrm{RH}$ change can be expressed as

$$
\Delta R_{\mathrm{RH}}=K_{\log (Q)} \Delta \log (\mathrm{RH}) .
$$

Equation (10) clearly reveals that the spectral RH radiative kernel is the same as the one for specific humidity. Thus, we can interpret Fig. 1, which shows the globally averaged specific humidity radiative kernel, as the RH kernel as well. RH changes at different vertical levels contribute differently to TOA flux changes over different spectral bands. Channels in the far-IR water vapor pure rotational band $\left(10-600 \mathrm{~cm}^{-1}\right)$ and the mid-IR water vapor $v_{2}$ band $\left(1300-1900 \mathrm{~cm}^{-1}\right)$ are mostly sensitive to relative humidity changes in the upper and middle troposphere, while channels in the window regions $\left(800-1200 \mathrm{~cm}^{-1}\right)$ are affected most by water vapor continuum absorptions and thus are sensitive to the lower troposphere, especially the planetary boundary layer.

\section{Results and discussion}

\section{a. Features of spectral and spatial distribution of $R H$ feedbacks}

Table 2 lists the global average of broadband RH feedbacks for the 16 GCMs. The broadband RH feedback is merely an integration of spectral RH feedbacks against wavenumber over the entire longwave spectrum. All models have broadband RH feedbacks within $\pm 0.1 \mathrm{~W} \mathrm{~m}^{-2} \mathrm{~K}^{-1}$ except the MPI-ESM-LR model. The ensemble mean of broadband $\mathrm{RH}$ feedback is only $-0.00085 \mathrm{~W} \mathrm{~m}^{-2} \mathrm{~K}^{-1}$ with a standard deviation of $0.072 \mathrm{~W} \mathrm{~m}^{-2} \mathrm{~K}^{-1}$. Excluding the obvious outlier, $0.21 \mathrm{~W} \mathrm{~m}^{-2} \mathrm{~K}^{-1}$ for the MPI-ESM-LR model, the ensemble mean of broadband $\mathrm{RH}$ feedback becomes $-0.015 \mathrm{~W} \mathrm{~m}^{-2} \mathrm{~K}^{-1}$ with a standard deviation of $0.047 \mathrm{~W} \mathrm{~m}^{-2} \mathrm{~K}^{-1}$, still insignificantly different from zero. Such nearly zero RH feedback is consistent with the well-known "constant RH" scenario. The spectral details of such globally averaged $\mathrm{RH}$ feedbacks are shown in Fig. 2a, with the ensemble mean and standard deviation across the 16 GCMs shown in Fig. 2b. The most striking feature in Fig. 2a is that spectral RH feedbacks of different GCMs vary quite differently with the frequency, in spite of their broadband integrations all being so close to zero. As is evident

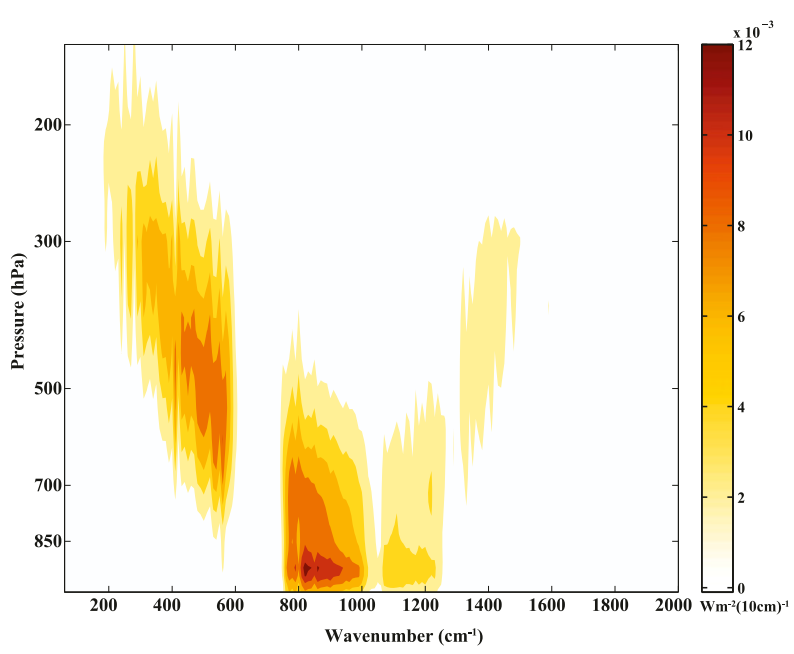

FIG. 1. Global average of the spectral radiative kernel for specific humidity as well as relative humidity. It is the global average response of TOA spectral flux averaged within spectral bins of $10 \mathrm{~cm}^{-1}$ to the change of the logarithm of $\mathrm{RH}$ at each pressure level. 
TABLE 2. Global average of broadband RH feedbacks $\left(\mathrm{W} \mathrm{m}^{-2} \mathrm{~K}^{-1}\right.$ ) for 16 CMIP5 GCMs.

\begin{tabular}{lrlc}
\hline \hline BCC_CSM1.1 & -0.033 & GISS-ES-R & 0.037 \\
BNU-ESM & 0.047 & HadGEM2-ES & -0.011 \\
CanESM2 & 0.059 & INM-CM4.0 & 0.0084 \\
CCSM4 & -0.062 & IPSL-CM5A-LR & -0.022 \\
CESM1(CAM5) & -0.094 & MIROC5 & -0.0027 \\
CNRM-CM5 & -0.018 & MPI-ESM-LR & 0.21 \\
GFDL CM3 & -0.021 & MRI-CGCM3 & -0.071 \\
GISS-E2-H & 0.036 & NorESM1-M & -0.076 \\
\hline
\end{tabular}

from Fig. 2b, for a majority part of the longwave spectrum, the spread of RH feedbacks among GCMs (as measured by the standard deviation) is larger than the model ensemble mean. Another salient feature in Fig. 2a is that, for a model with positive (negative) broadband RH feedback, its spectral decomposition is not necessarily always positive (negative).

Figure 3 shows the global maps of ensemble-mean broadband $\mathrm{RH}$ feedbacks as well as the spectral $\mathrm{RH}$ feedbacks for three bands, 60-300, 400-600, and 800$1100 \mathrm{~cm}^{-1}$. The three bands are chosen because, as shown in Fig. 1, they are sensitive to the upper, middle, and lower troposphere respectively. Areas with statistically significant nonzero ensemble mean (99\% significance level based on the Student's $t$ test) are stippled with dots. Two major findings can be concluded from Fig. 3:

1) For the broadband and all spectral bands shown here, the magnitude of local RH feedback is much greater than that of the global average. Some regions exhibit positive RH feedbacks while other regions have negative $\mathrm{RH}$ feedbacks with comparable magnitude. Thus, Figs. 2 and 3 indicate that the nearly zero global average of broadband $\mathrm{RH}$ feedback is a result of spatial compensation and spectral compensation.

2) Spatial patterns of RH feedbacks vary noticeably with the spectral band. For the spectral band of $60-300 \mathrm{~cm}^{-1}$, the most noticeable patterns are significantly positive RH feedbacks at high latitudes $\left(60^{\circ}-90^{\circ}\right.$ for both hemispheres) and comparable negative RH feedbacks in part of tropical Atlantic $\left(5^{\circ}-20^{\circ} \mathrm{N}\right.$ and $\left.5^{\circ}-20^{\circ} \mathrm{S}, 300^{\circ}-350^{\circ} \mathrm{E}\right)$. For the other two spectral bands, the most noticeable spatial pattern is the significantly positive feedback confined in the deep tropical Pacific $\left(5^{\circ} \mathrm{S}-5^{\circ} \mathrm{N}, 200^{\circ}-250^{\circ} \mathrm{E}\right)$. For other geographical regions not mentioned above, like the midlatitudes and the subtropics $\left(20^{\circ}-40^{\circ}\right)$ in both hemispheres, the ensemble-mean $\mathrm{RH}$ feedbacks are not significantly different from zero based on the Student's $t$ test that we performed. In other words, there is no consensus among the GCMs as to whether the $\mathrm{RH}$ feedbacks in such regions are positive or negative under the global warming scenario.

\section{b. Relationships between the mean spectral $R H$ feedbacks and mean RH changes}

The three spectral bands examined in the previous section are sensitive to water vapor emission and absorption in different parts of the atmosphere as mentioned above. The $60-300 \mathrm{~cm}^{-1}$ band is most sensitive to the upper troposphere, the $400-600 \mathrm{~cm}^{-1}$ to the middle troposphere, and the $800-1100 \mathrm{~cm}^{-1}$ to the boundary layer (water vapor continuum absorption). Figure 4 then shows ensemble-mean changes in RH at 300, 500, and $850 \mathrm{hPa}$ from years $1-20$ to years $61-80$ in the 80 years of the $1 \% \mathrm{CO}_{2}$ simulation experiment (the stippled area is statistically significant at the $99 \%$ significance level). The similarity between Fig. 3 and Fig. 4 is self-evident. At $300 \mathrm{hPa}$, the ensemble mean exhibits a significant increase of $\mathrm{RH}$ in the high latitudes $\left(60^{\circ}-90^{\circ}\right.$ for both hemispheres) and comparable decrease of RH in part of the tropical Atlantic $\left(5^{\circ}-20^{\circ} \mathrm{N}\right.$ and $\left.5^{\circ}-20^{\circ} \mathrm{S}, 300^{\circ}-350^{\circ} \mathrm{E}\right)$. At $500 \mathrm{hPa}$, there is little $\mathrm{RH}$ change in high latitudes while the most obvious feature is increased $\mathrm{RH}$ in the deep tropical Pacific $\left(5^{\circ} \mathrm{S}-5^{\circ} \mathrm{N}, 200^{\circ}-250^{\circ} \mathrm{E}\right)$. At $850 \mathrm{hPa}$, a statistically significant increase (decrease) of $\mathrm{RH}$ is seen in the deep tropical Pacific (part of the subtropics). The spatial features of RH changes at the three pressure levels correlate well with those of spectral RH feedbacks shown in Fig. 3 for the three spectral bands, supporting the advantage of spectral over broadband $\mathrm{RH}$ feedbacks for inspecting $\mathrm{RH}$ changes.

Within one grid box, RH changes at different levels lead to TOA flux changes at different frequencies, leaving an approximate linear relationship between the spectral RH feedback and vertical profile of RH changes. Regarding mean value averaged over a large climate domain, it is meaningful to examine whether there still exists a relationship between the vertical profile of mean RH change and the spectral decomposition of mean broadband RH feedback. The GCMs examined here have produced consistent RH feedbacks and RH changes to a large extent in the high latitudes, the tropical Atlantic, and the deep tropical Pacific. Thus, we are motivated to further seek quantitative ways to infer regional RH changes from the spectral RH feedbacks averaged in such three broad geographical regions. Since we work with the CMIP5 simulation data, the actual RH change is already known. Thus it gives us an opportunity to examine how well an inversion of mean spectral radiative feedback can render the vertical profile of mean RH change. 
a)

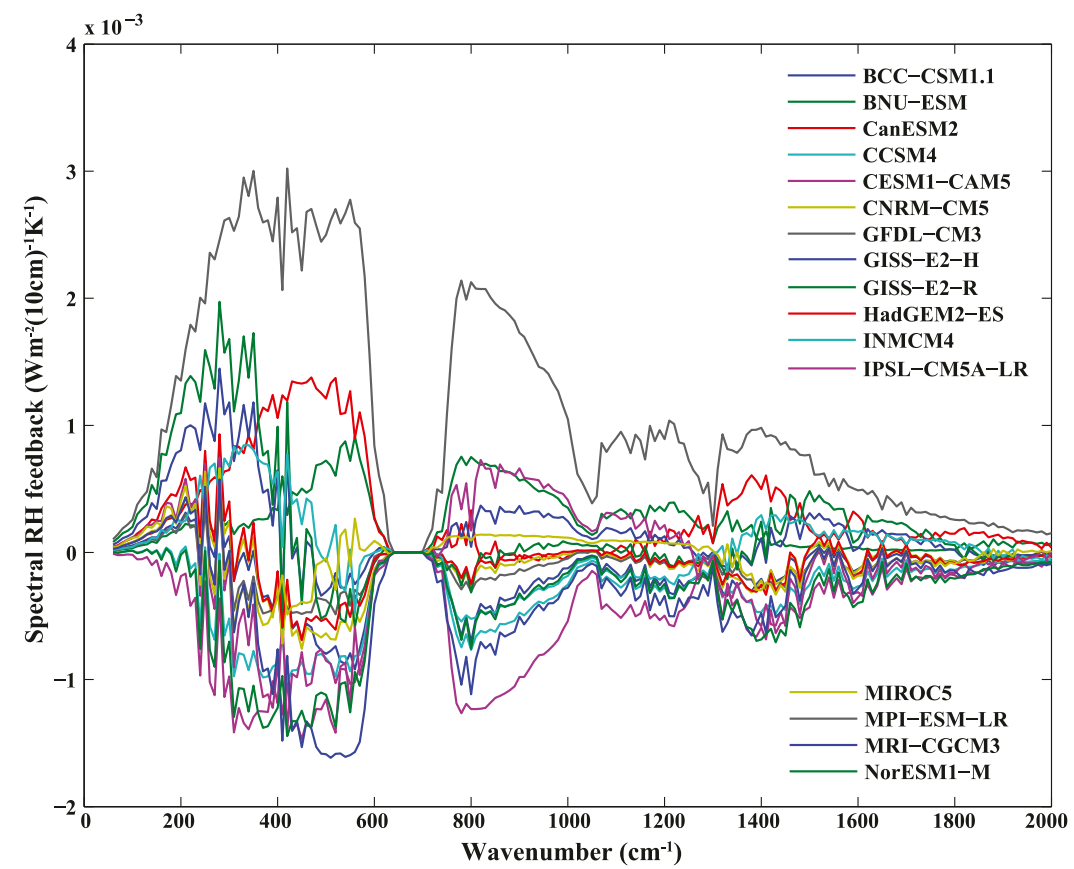

b)

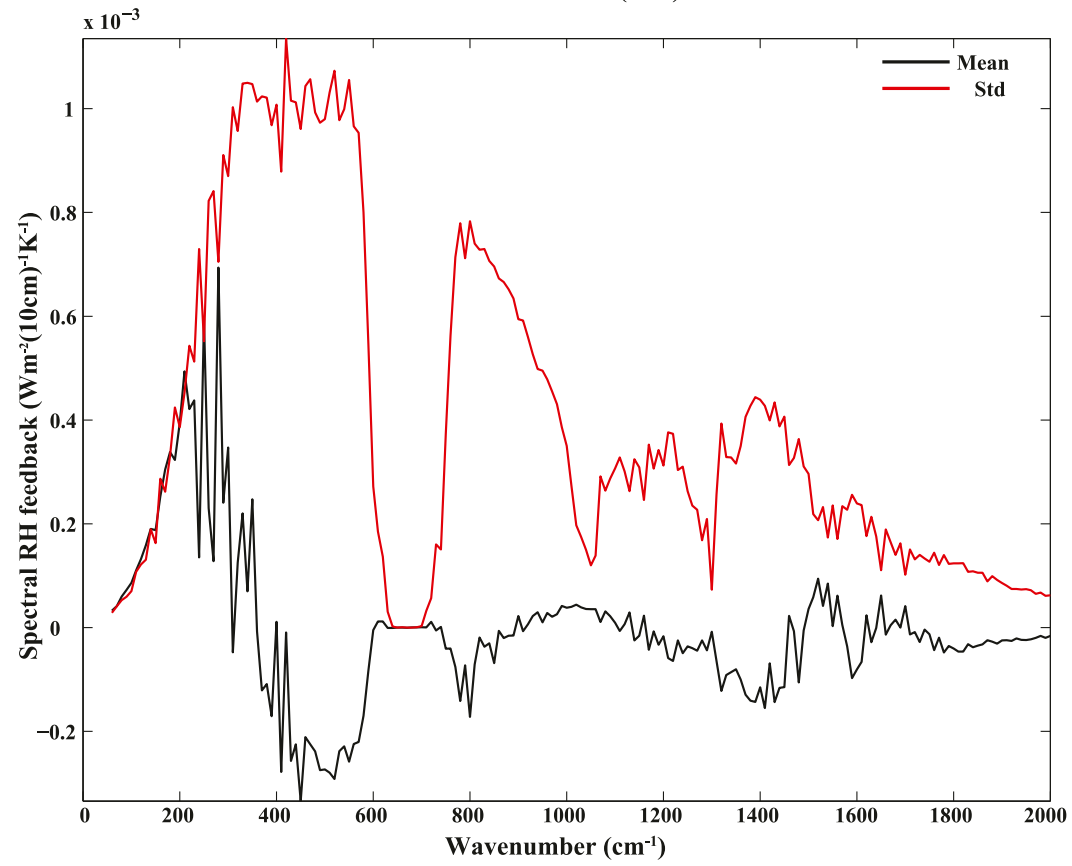

FIG. 2. (a) Global average of spectral RH feedbacks for the 16 GCMs in the CMIP5 archive. (b) Model ensemble mean and standard deviation of the global average of spectral RH feedbacks in 16 GCMs.

For the inversion here, we estimate the changes in $\mathrm{RH}$ at different pressure levels from the spectral RH feedbacks by inverting the average of spectral radiative kernel $K$ and multiplying by the TOA flux changes in the given region (i.e., the high latitudes, the tropical Atlantic, and the deep tropical Pacific). Two methods are used here for the inversion: the constrained inversion method (Twomey 1977) and the truncated singular value decomposition (SVD) method (Hansen 1990). Appendix A describes the mathematics of the two methods in detail.

In the following discussion about quantitatively inferring $\mathrm{RH}$ changes from the regional-averaged spectral $\mathrm{RH}$ feedbacks, we first examine the relationship 

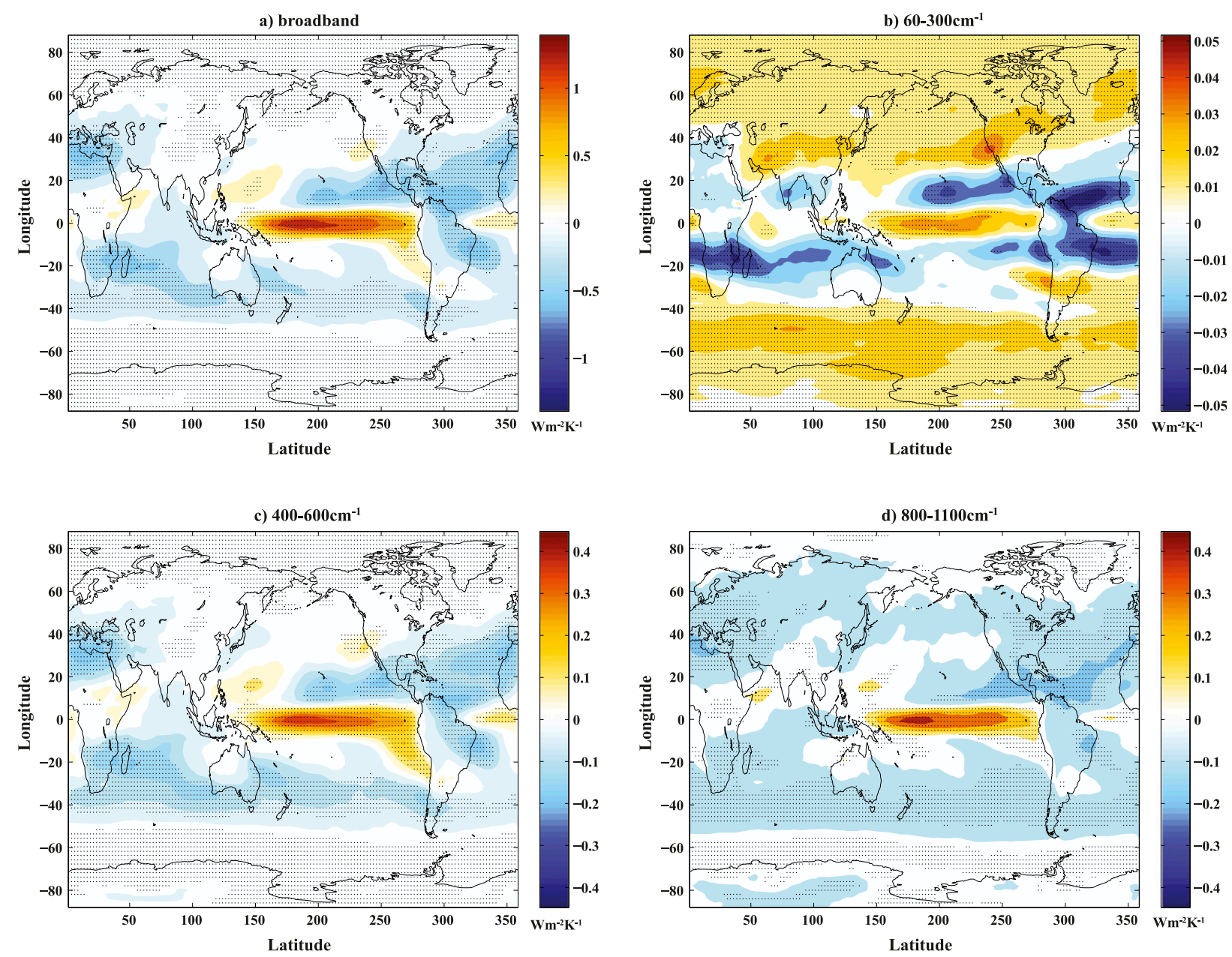

FIG. 3. The global map of model-mean RH feedbacks from the 16 GCMs over different spectral bands: (a) broadband (60-2000 $\mathrm{cm}^{-1}$ ) and (b) 60-300, (c) 400-600, and (d) $800-1100 \mathrm{~cm}^{-1}$. The areas where RH feedbacks are nonzero at the $99 \%$ significance level are stippled by dots.

between the spectral feature of multimodel ensemble mean RH feedbacks and the vertical feature of mean $\mathrm{RH}$ changes. Then we inspect the standard deviation of model ensembles (measured against the ensemble mean) to examine whether the spread of spectral RH feedbacks among models is consistent with the spread of vertical RH changes. Finally, we use a Taylor diagram approach to explore how well the spectral decomposition of RH feedbacks can render the vertical profile of RH changes.

Before we embark on retrieving the regional $\mathrm{RH}$ changes from the spectral RH feedbacks, one implicit linearity assumption needs to be validated: the average of TOA flux changes due to $\mathrm{RH}$ perturbations for a given geographical region can be well approximated by the product of the average of spectral $\mathrm{RH}$ kernels and the average of $\mathrm{RH}$ perturbations over the same region. Appendix B discusses how to test this assumption and shows why the linearity assumption is valid for the aforementioned three regions.

\section{1) High LATITUdes $\left(60^{\circ}-90^{\circ}\right.$ FOR BOTH HEMISPHERES)}

The left column in Fig. 5 shows the ensemble means of spectral RH feedbacks averaged over the high latitudes for both hemispheres. Two notable spectral features are that 1 ) $\mathrm{RH}$ feedbacks are positive almost across the whole spectrum and 2) two bands, $60-600 \mathrm{~cm}^{-1}$ and $1200-2000 \mathrm{~cm}^{-1}$, dominate the broadband RH feedback while the contribution from $800-1200 \mathrm{~cm}^{-1}$ is negligible. As mentioned in section $3 \mathrm{~b}$, different spectral bands are sensitive to water vapor emission and absorption in different parts of the atmosphere. Based on the spectral features, we can infer two features about the $\mathrm{RH}$ changes in the high latitudes: 1) RH changes are positive in almost the whole troposphere and 2) dominant 

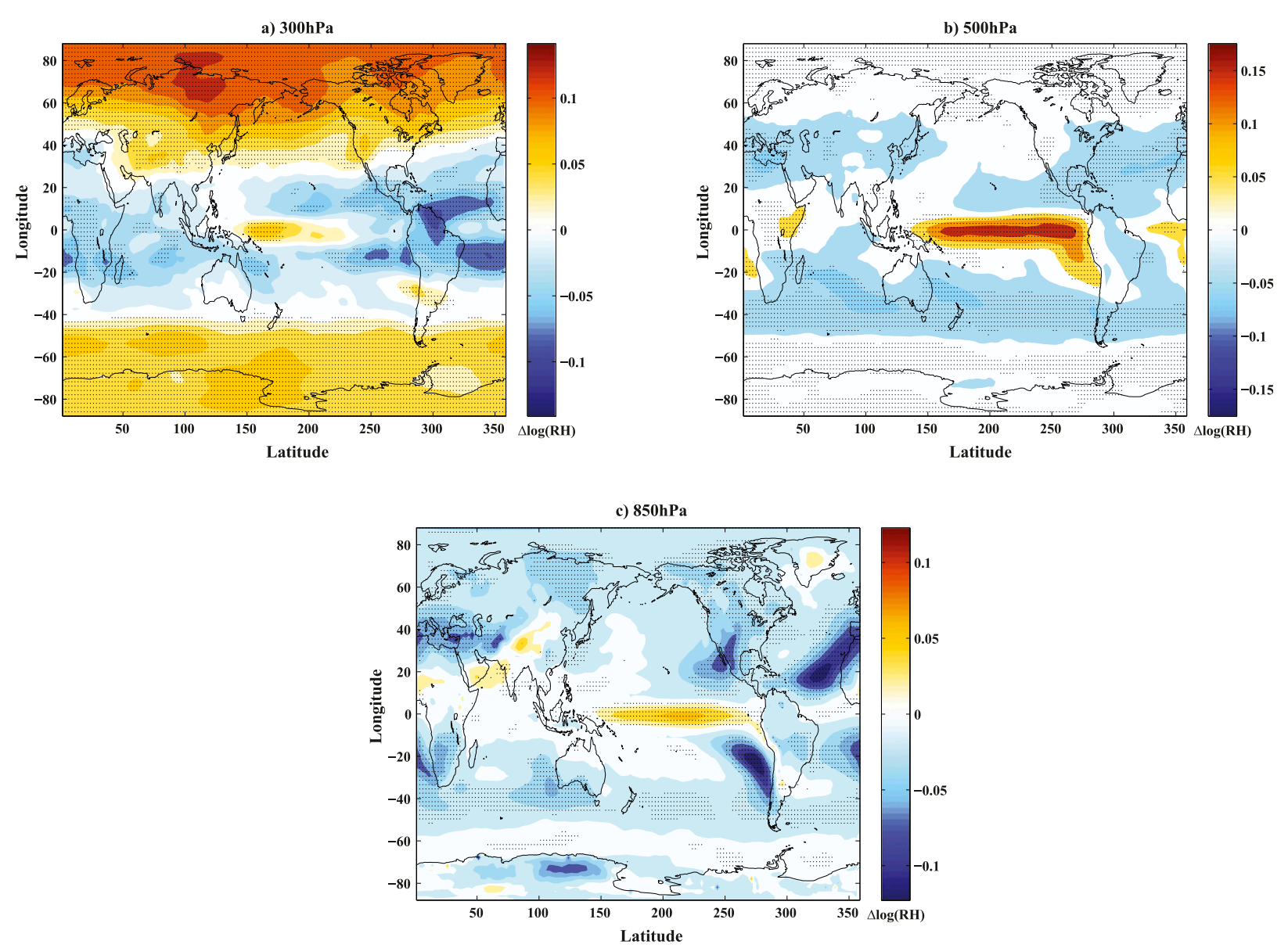

FIG. 4. The global map of model-mean fractional change of RH among 16 GCMs from years 1-20 to years 60-80 in the experiments with a $1 \% \mathrm{CO}_{2}$ increase per year at (a) 300 , (b) 500 , and (c) $850 \mathrm{hPa}$. The areas where the $\mathrm{RH}$ changes are nonzero at the $99 \%$ significance level are stippled by dots.

changes occur in the upper troposphere. The right column in Fig. 5 shows ensemble-mean profiles of local $\mathrm{RH}$ changes in the high latitudes for both hemispheres. The RH changes are obtained by averaging the direct outputs from 16 GCMs (the truth) and retrieved from corresponding spectral $\mathrm{RH}$ feedbacks using the two methods introduced in appendix A (the retrievals). Both the retrieved and actual profiles are consistent with the qualitative inference of RH changes from the spectral features mentioned above: in most part of troposphere the $\mathrm{RH}$ changes are positive and the $\mathrm{RH}$ changes are more prominent in the upper troposphere than in the lower troposphere, with the largest change at around $300 \mathrm{hPa}$.

Figure 5 also shows the standard deviation of regional spectral RH feedbacks and RH changes among the 16 GCMs. Comparing the magnitude of the standard deviation to the model ensemble mean can help reveal the consistency of RH feedbacks or RH changes among GCMs. From 800 to $1200 \mathrm{~cm}^{-1}$, the ensemble mean of spectral RH feedbacks is larger than the standard deviation in the Southern Hemisphere high latitudes but this is not the case in the Northern Hemisphere. Correspondingly, between 600 and $700 \mathrm{hPa}$ there is a large spread of RH changes among GCMs in the Northern Hemisphere. This can be seen from the right column of Fig. 5 as the ensemble mean of RH changes is smaller than standard deviation in the Northern Hemisphere.

Figures $6 a$ and $6 b$, in a Taylor diagram style, summarize how well our inversion of spectral radiative feedback can render the vertical profile of $\mathrm{RH}$ changes for each individual GCM. The performances of inversion techniques, measured in a Taylor diagram manner (correlation for pattern matching and standard deviation for magnitude matching), are similar for most GCMs. First, correlations between the retrieved profiles and actual ones range from 0.7 to 0.9 , suggesting that our inversion can generally retrieve the vertical distribution of RH changes from the spectral RH feedbacks. Second, the ratio of standard deviations of retrieved RH changes to actual changes is smaller than 1 in all GCMs with one 
a).

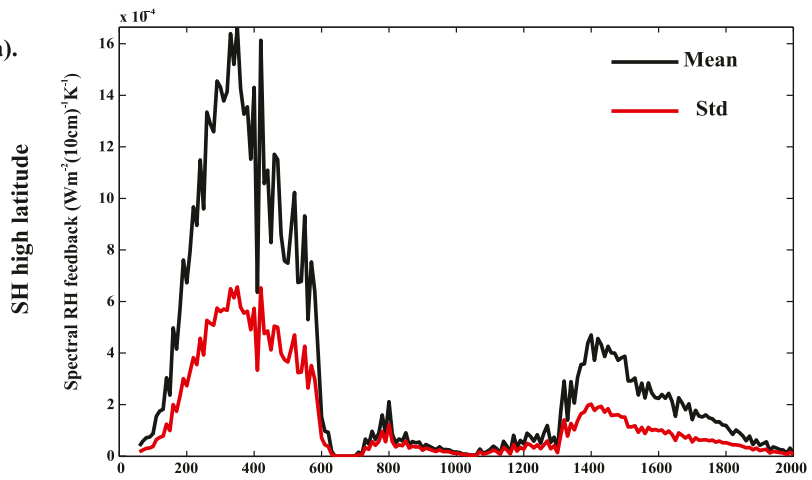

b).

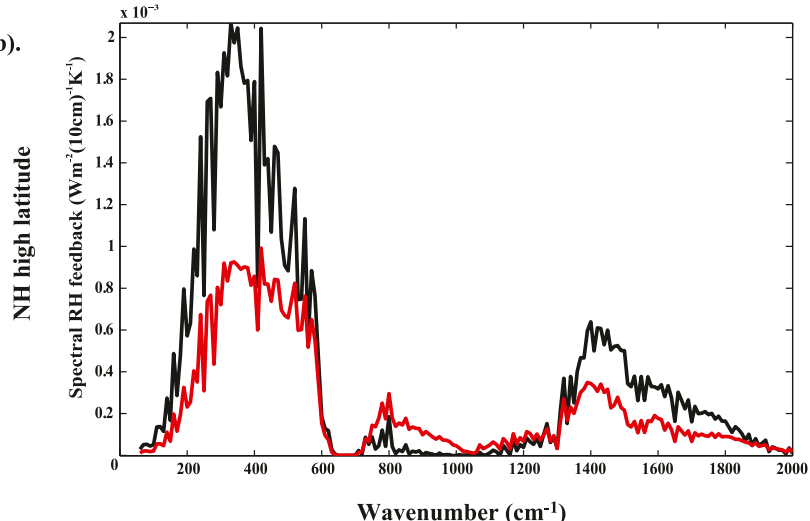

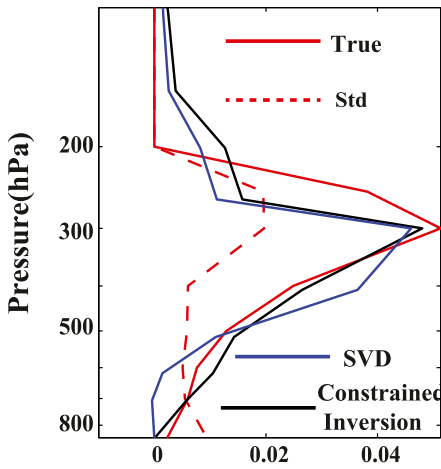

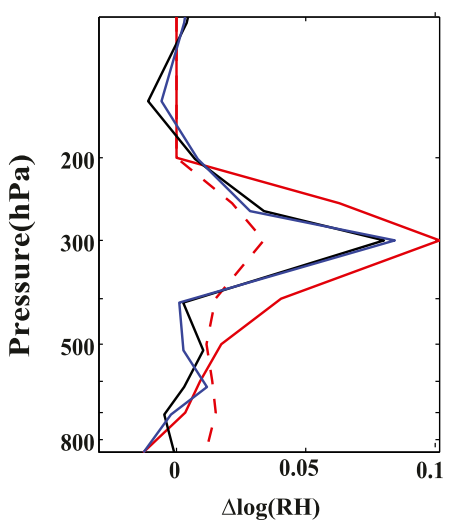

FIG. 5. (left) Model ensemble mean (black line) and standard deviation (red line) of regional spectral RH feedbacks among 16 GCMs in the high-latitude (a) Southern Hemisphere and (b) Northern Hemisphere. (right) Model-mean profiles of regional RH changes from the years 1-20 to years 60-80 output from the experiments with a $1 \% \mathrm{CO}_{2}$ increase per year in $16 \mathrm{GCMs}$ (red line), retrieved from the regional spectral $\mathrm{RH}$ feedbacks by the constrained inversion method (black line) and by the truncated SVD method (blue line) in the regions corresponding to the left column. The standard deviation of actual profiles of regional RH changes among the $16 \mathrm{GCMs}$ (corresponding to the red line) is shown by a red dashed line.

exception. A possible reason is that our inversion tends to overly smooth the vertical variation of RH changes.

\section{2) TROPICAL ATLANTiC $\left(5^{\circ}-20^{\circ} \mathrm{S}\right.$ AND $5^{\circ}-20^{\circ} \mathrm{N}$, $\left.300^{\circ}-350^{\circ} \mathrm{E}\right)$}

Similar to Fig. 5, Fig. 7 shows the ensemble mean of regional spectral RH feedbacks for the tropical Atlantic in both hemispheres. Compared to Fig. 5, the spectral features here are noticeably different. In most models, spectral RH feedbacks are negative across the whole spectrum. Moreover, in the tropical Atlantic, the contribution from $800-1200 \mathrm{~cm}^{-1}$ to the broadband RH feedback strength is comparable to those from $60-600 \mathrm{~cm}^{-1}$ and $1200-2000 \mathrm{~cm}^{-1}$. These spectral features imply that 1 ) $\mathrm{RH}$ changes are negative at almost all levels in most models and 2) the RH changes in the planetary boundary layer and in the free troposphere contribute comparably to the changes of TOA longwave flux. These inferences are quantitatively corroborated by the retrieval results shown in the right column of Fig. 7. The retrievals show that the ensemble-mean RH change is indeed negative through the entire troposphere and there are two peaks of $\mathrm{RH}$ reduction, one in the boundary layer and the other in the upper troposphere above $400 \mathrm{hPa}$.

Compared to the RH feedbacks in the high latitudes, there is a large spread among GCMs in the tropical Atlantic. In the left column of Fig. 7 the magnitude of the standard deviation is comparable to the model ensemble mean over many frequency regions, noticeably near $60 \mathrm{~cm}^{-1}$ (sensitive to emissions from the upper troposphere), near $600 \mathrm{~cm}^{-1}$ (sensitive to emissions from $500-700 \mathrm{hPa}$ ), and at $800-1200 \mathrm{~cm}^{-1}$ (sensitive to surface emission). These suggest large intermodel spreads for the RH changes in the upper troposphere, in the layer of $500-700 \mathrm{hPa}$, and in the planetary boundary layer for the tropical Atlantic. The actual standard deviations shown in the right column confirm such an inference about the intermodel spread.

The evaluations of our retrieved profiles of $\mathrm{RH}$ changes for each GCM are shown in Figs. $6 \mathrm{c}$ and $6 \mathrm{~d}$. 
a) SH high latitude

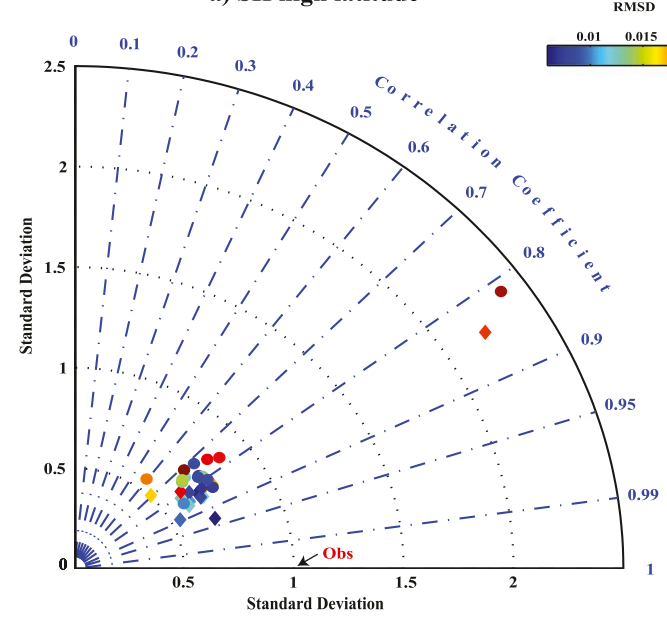

c) SH tropical Atlantic

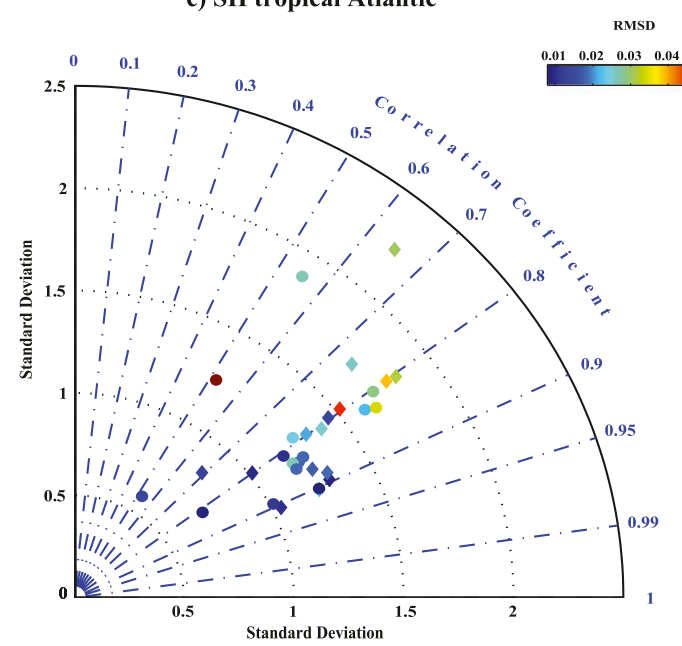

b) NH high latitude

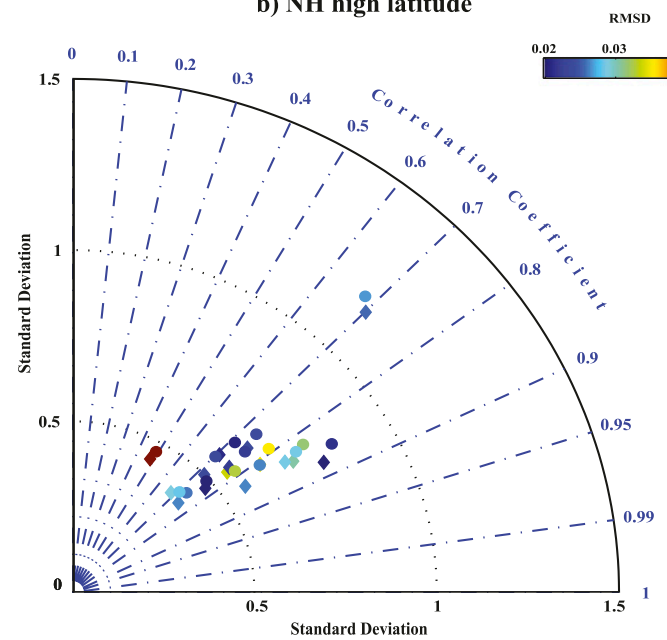

d) NH tropical Atlantic

RMSD

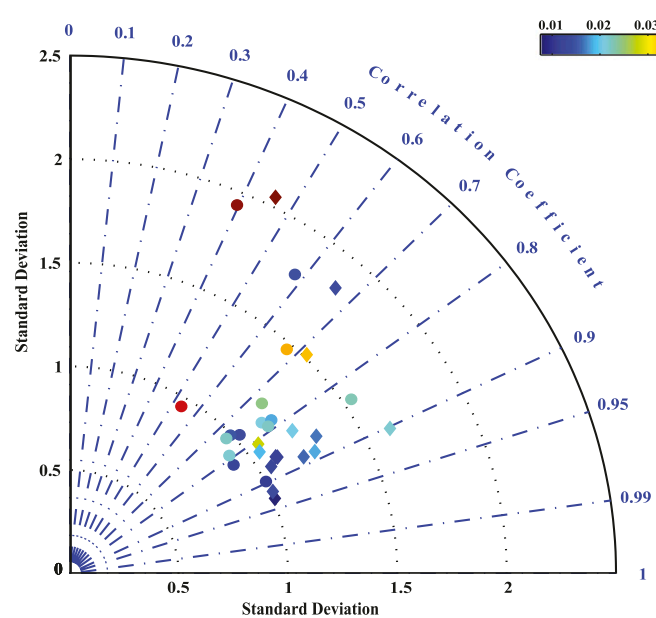

e) Deep tropical Pacific

RMSD

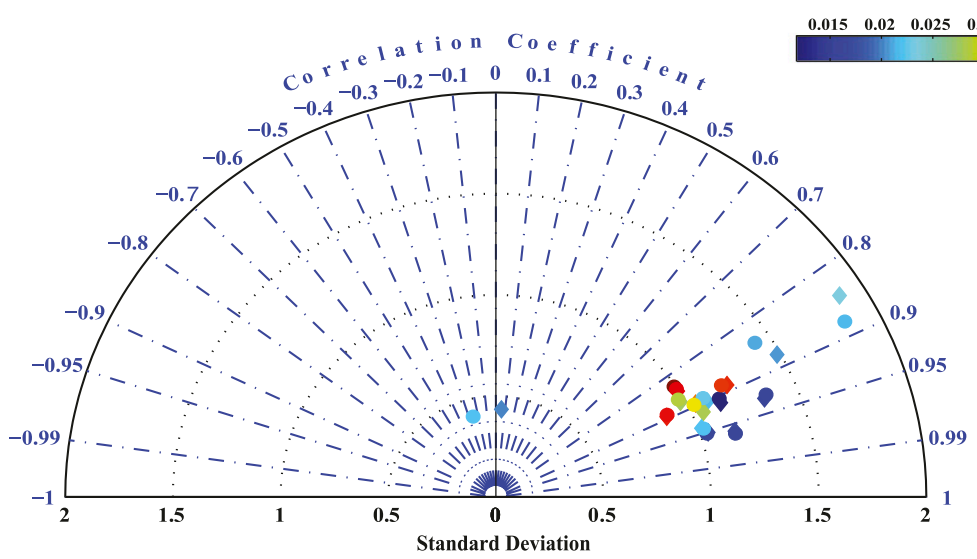

FIG. 6. (a)-(e) Taylor diagrams to evaluating retrieved profiles of regional RH changes in the 16 GCMs between years $60-80$ and years 1-20 of the $1 \% \mathrm{CO}_{2}$ increase per year simulation. The distance between each point and the point labeled "Obs" as illustrated in (a) is a measure of how the retrieved profiles in each model reproduce the true RH changes. The correlation coefficient (similarity between the retrievals and true values) is related to the azimuthal angle; the ratio of standard deviation of retrievals to the true values is proportional to the radial distance from the origin. The retrieved profiles of $\mathrm{RH}$ change from regional spectral $\mathrm{RH}$ feedbacks are obtained by the constrained inversion method (diamond) and by the truncated SVD method (circle). The color demonstrates the root-mean-square deviation from true RH changes in 16 GCMs. 

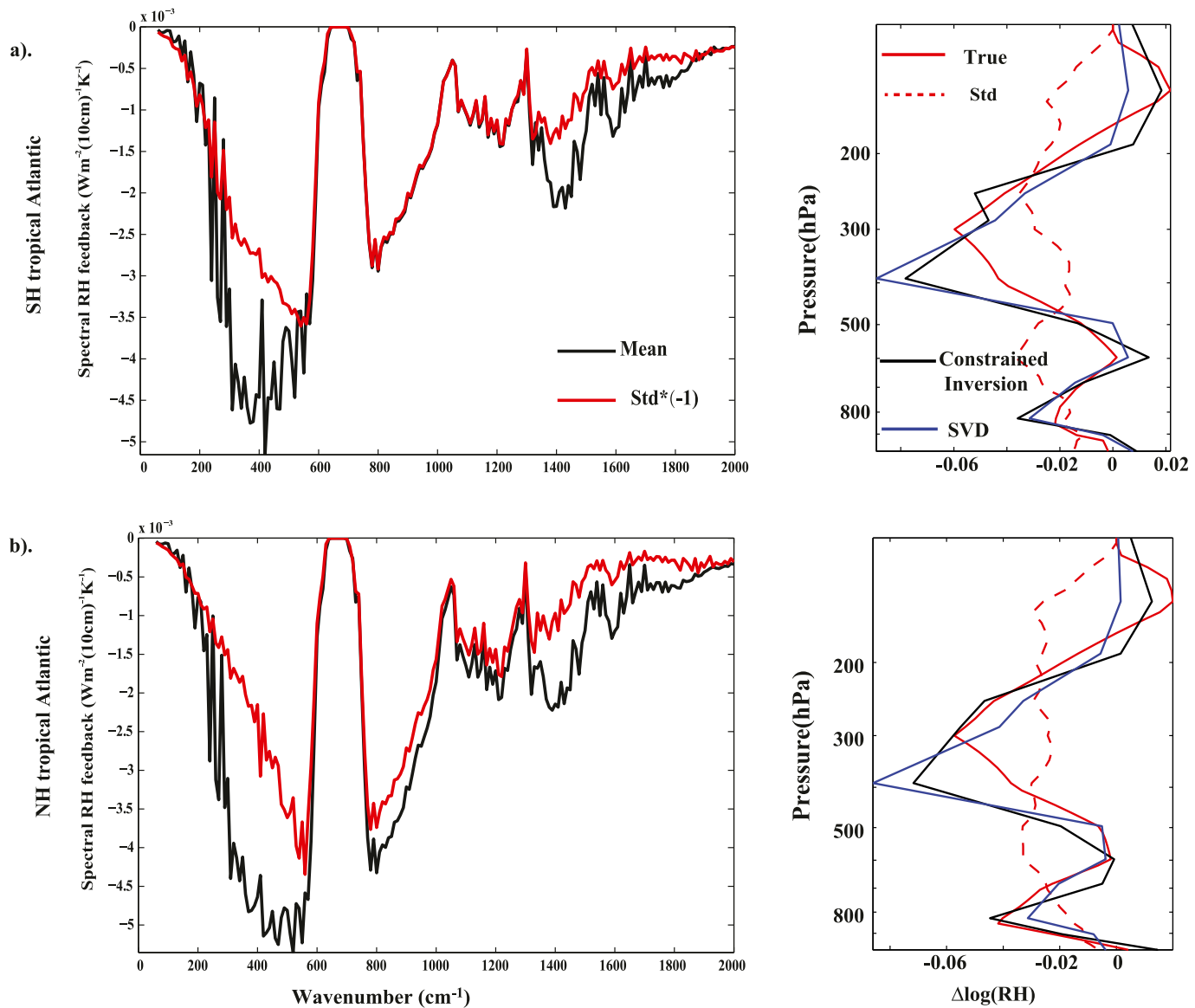

FIG. 7. As in Fig. 5, but for the tropical Atlantic. In the left column, the standard deviation is multiplied by -1 for the convenience of comparison.

The correlations between our retrieved profiles and actual ones are generally in the range of 0.7-0.9. However, for several models the inversion of spectral $\mathrm{RH}$ feedbacks poorly reproduces the actual $\mathrm{RH}$ changes when the correlations are smaller than 0.7 . Moreover, for most models our inversion overestimates the magnitude of the vertical RH changes (the ratio of retrievals to actual ones is larger than 1). A possible reason for these biases is that the linearity assumption for retrieving mentioned at the beginning of section $3 \mathrm{~b}$ is not applicable to the tropical Atlantic. Further discussion about this can be found in appendix B. Although the nonlinearity impedes an accurate inversion from mean spectral RH feedback to mean RH changes, Fig. 7 still shows that the spectral decomposition of broadband RH feedback can reveal reasonable information about vertical features of RH changes.

\section{3) DeEP tropical PaCiFIC $\left(5^{\circ} \mathrm{S}-5^{\circ} \mathrm{N}, 200^{\circ}-250^{\circ} \mathrm{E}\right)$}

Similar to Fig. 5, Fig. 8 shows the ensemble mean of the spectral RH feedbacks over the deep tropical Pacific. The feedback is positive across the entire spectrum. The spectral contribution from $800-1200 \mathrm{~cm}^{-1}$ to the broadband $\mathrm{RH}$ feedback is comparable to that from 60 to $600 \mathrm{~cm}^{-1}$. From 60 to $600 \mathrm{~cm}^{-1}$, the spectral RH feedback monotonically increases with frequency. Note, from 60 to $600 \mathrm{~cm}^{-1}$, the height of maximum sensitivity of TOA spectral flux to RH change monotonically descends from the upper to the middle troposphere (refer to Fig. 1). This is different from the case of the high latitudes, where the peak of spectral RH feedback in the far IR is between 300 and $400 \mathrm{~cm}^{-1}$. These spectral features imply that, in the deep tropical Pacific, the RH changes are positive at almost all levels in the troposphere and there is considerable contribution from the middle-tropospheric $\mathrm{RH}$ changes to the broadband $\mathrm{RH}$ feedbacks. These inferences are confirmed by the profiles of RH changes in the right column of Fig. 8. The change in $\mathrm{RH}$ indeed peaks at $500 \mathrm{hPa}$, lower than the peak for the high-latitude RH change (Fig. 5).

GCMs agree to a very large extent on the RH feedbacks in the deep tropical Pacific. The ensemble mean of spectral $\mathrm{RH}$ feedbacks is larger than the standard deviation over 

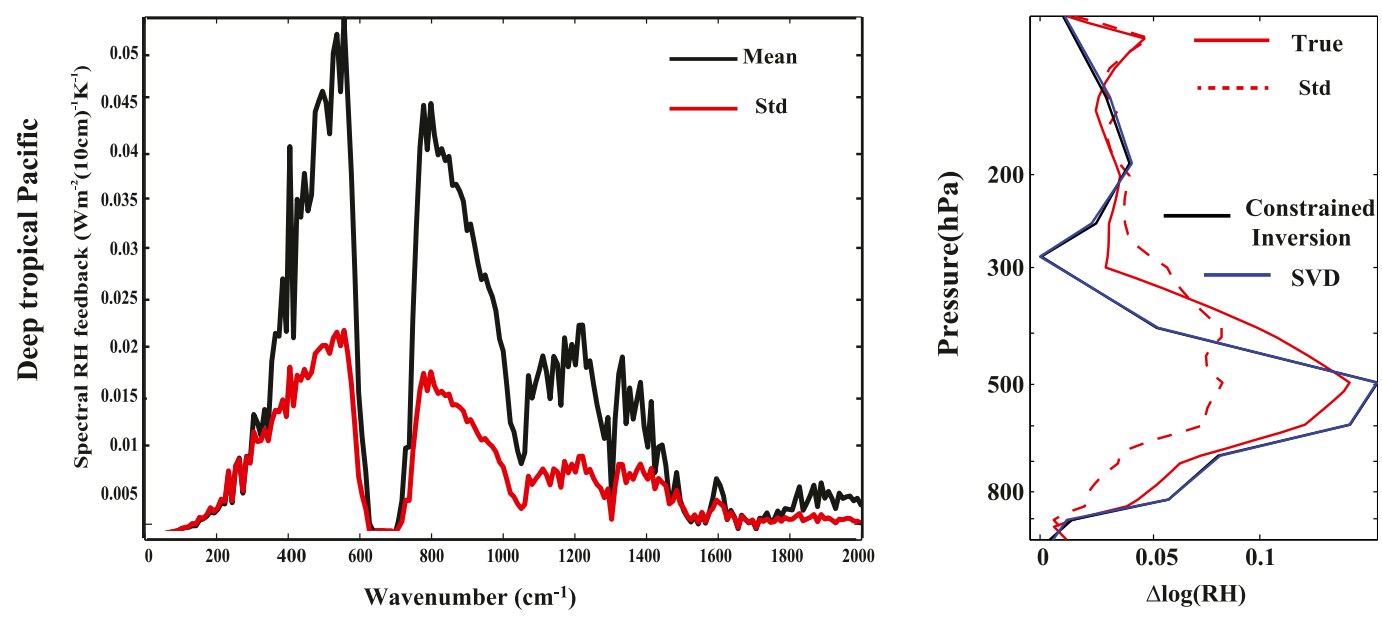

FIG. 8. As in Fig. 5, but for the deep tropical Pacific.

almost the entire spectrum, especially in $400-600 \mathrm{~cm}^{-1}$ and $800-1200 \mathrm{~cm}^{-1}$. Thus the vertical RH change in the most of troposphere should be consistent among GCMs, which is confirmed by the plots in the right column of Fig. 8 .

Evaluations of our retrieved RH changes for individual GCMs are shown in Fig. 6e. Inversion performance is generally satisfactory. For most GCMs, the correlation between our retrieved profiles and actual ones is around 0.9 with the ratio of standard deviations being close to one. Among three regions examined here, the inversion technique performs the best for the deep tropical Pacific. In other words, in the deep tropical Pacific the spectral decomposition of broadband $\mathrm{RH}$ feedbacks is most linearly proportional to the changes in $\mathrm{RH}$ vertical profile.

\section{Conclusions and discussion}

We use the spectral radiative kernel technique to derive spectrally resolved RH feedbacks for 16 GCMs in the CMIP5 archives. As expected, globally averaged broadband RH feedback is nearly zero for the GCMs. However, after spectral decomposition of broadband RH feedback, wide discrepancies are revealed among GCMs. Further spatial decomposition shows that regional broadband $\mathrm{RH}$ feedbacks are no longer nearly zero as is the global average. Spatial patterns of broadband RH feedbacks vary noticeably with the spectral region. A part of the far-IR band, $60-300 \mathrm{~cm}^{-1}$, exhibits positive RH feedbacks in the high latitudes and the deep tropical Pacific but negative $\mathrm{RH}$ feedbacks in the tropical Atlantic. The other part of the far-IR band $\left(400-600 \mathrm{~cm}^{-1}\right)$ and the window region (800-1200 $\mathrm{cm}^{-1}$ ) show statistically significant positive RH feedbacks in the deep tropical Pacific. The nearly zero global broadband RH feedback is a result of spatial compensation and spectral compensation.
We further utilize regional-averaged RH radiative kernels to analyze regional spectral RH feedbacks in the high latitudes, the tropical Atlantic, and the deep tropical Pacific, regions where GCMs produce RH feedbacks significantly different from zero. This exercise is used to further explore whether useful information about vertical feature of $\mathrm{RH}$ changes can be extracted from the spectral decomposition of heavily averaged fluxes. We retrieve profiles of $\mathrm{RH}$ changes using two approaches and check the consistency of retrievals with the actual ones from the GCM output. Although our retrieving methods do not take nonlinearity error into account, the results from both methods are consistent and demonstrate that $\mathrm{RH}$ changes in different parts of the troposphere can be attributed from the spectral decomposition of RH fluxes. Such additional information cannot be gleaned from broadband $\mathrm{RH}$ feedback studies alone. Further study on improving retrieving method possibly provides more accurate vertical profiles of mean $\mathrm{RH}$ changes.

Spectral decomposition of RH feedbacks reveals considerable intermodel differences that may be cancelled in the integration over broadband. The spectral feature of RH feedbacks is tightly related to the vertical feature of RH changes even averaged over a large climate domain. These advantages permit stricter evaluation of feedbacks in GCMs against observations. If we can separate the spectral signal of RH changes combined with changes in other feedback variables from observed TOA longwave spectral flux (Huang et al. 2010a,b; Kato et al. 2014), it is possible to provide an additional constraint, that is, a spectral constraint to climate models given the recent accumulation of highquality spectral radiance observations by the Atmospheric Infrared Sounder (AIRS; Chahine et al. 2006), the Infrared 

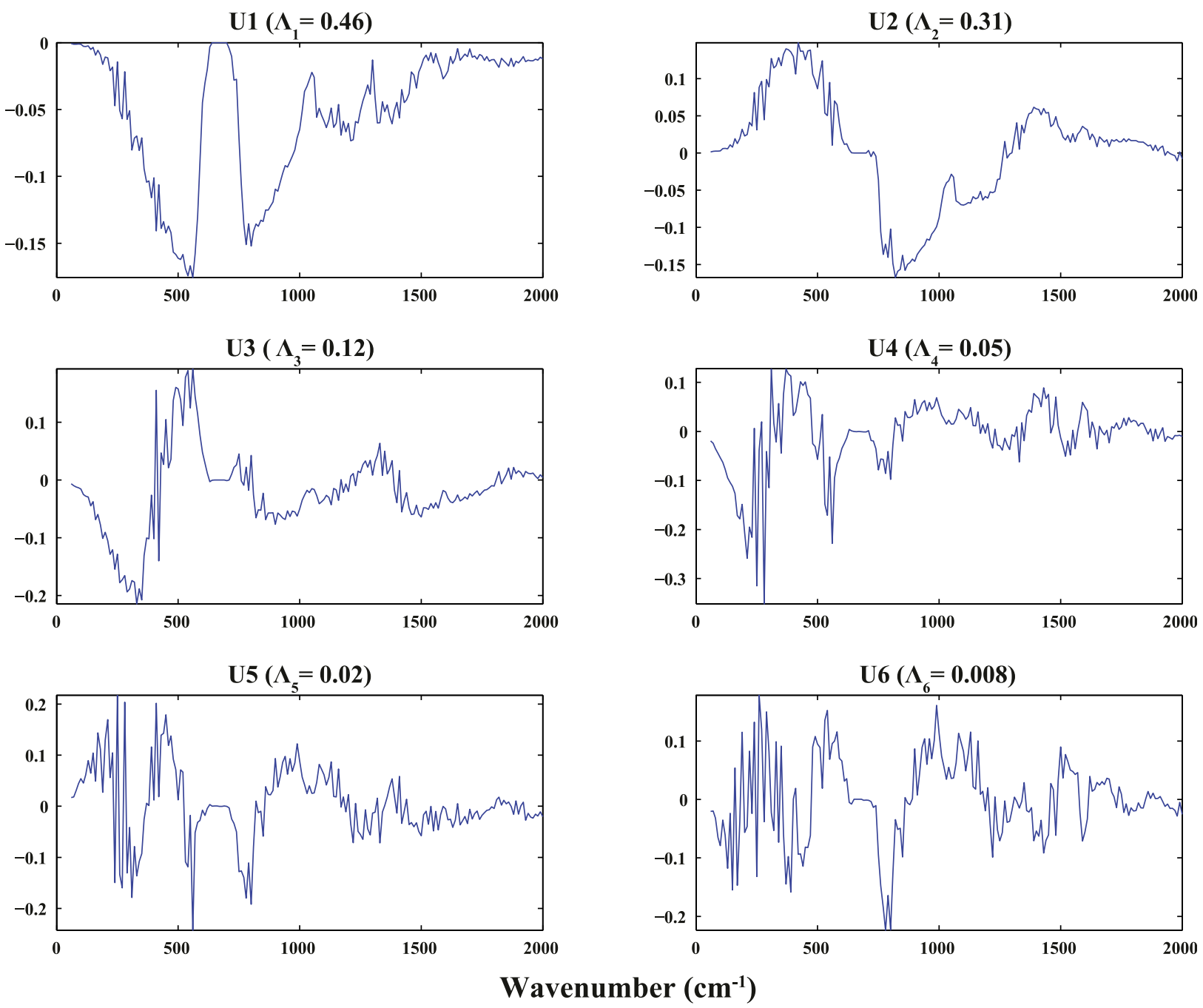

FIG. A1. The first six components of left singular vectors from the SVD of globally averaged RH radiative kernels, with their corresponding eigenvalues indicated.

Atmospheric Sounding Interferometer (IASI; Hilton et al. 2012), and the Cross-track Infrared Sounder (CrIS; Han et al. 2013).

Acknowledgments. We wish to thank three anonymous reviewers and editor Dr. Shell for their insightful and thorough comments. We acknowledge the modeling groups, the Program for Climate Model Diagnosis and Intercomparison (PCMDI) and WCRP's Working Group on Coupled Modeling (WGCM) for their roles in making available the WCRP CMIP5 multi-model datasets (data are available online at https://pcmdi.llnl.gov/ mips/cmip5/). This research is supported by NASA Terra/ Aqua program under Grant NNX14AJ50G awarded to the University of Michigan and was carried out when the lead author Pan was a Ph.D. student in the University of Michigan. Huang is also supported by the
NASA Terra/Aqua/Suomi-NPP program under Grant 80NSSC18K1033 awarded to the University of Michigan.

\section{APPENDIX A}

\section{Two Linear Inversion Methods}

To infer $\mathbf{x}$ from $\mathbf{y}$ when $\mathbf{y}$ is approximated by $\mathbf{K x}$, we implement two methods to invert $\mathbf{K}$ in this paper. First is the constrained inversion method (Twomey 1977). By this method,

$$
\mathbf{x}=\left(\mathbf{K}^{\mathrm{T}} \mathbf{K}+\lambda \mathbf{I}\right)^{-1} \mathbf{K}^{\mathrm{T}} \mathbf{y}
$$

where $\mathbf{I}$ is the identity matrix, and $\lambda$ can be obtained by minimizing the root-mean-square (RMS) deviation after calculating the RMS between the retrieved $\mathbf{x}$ and 

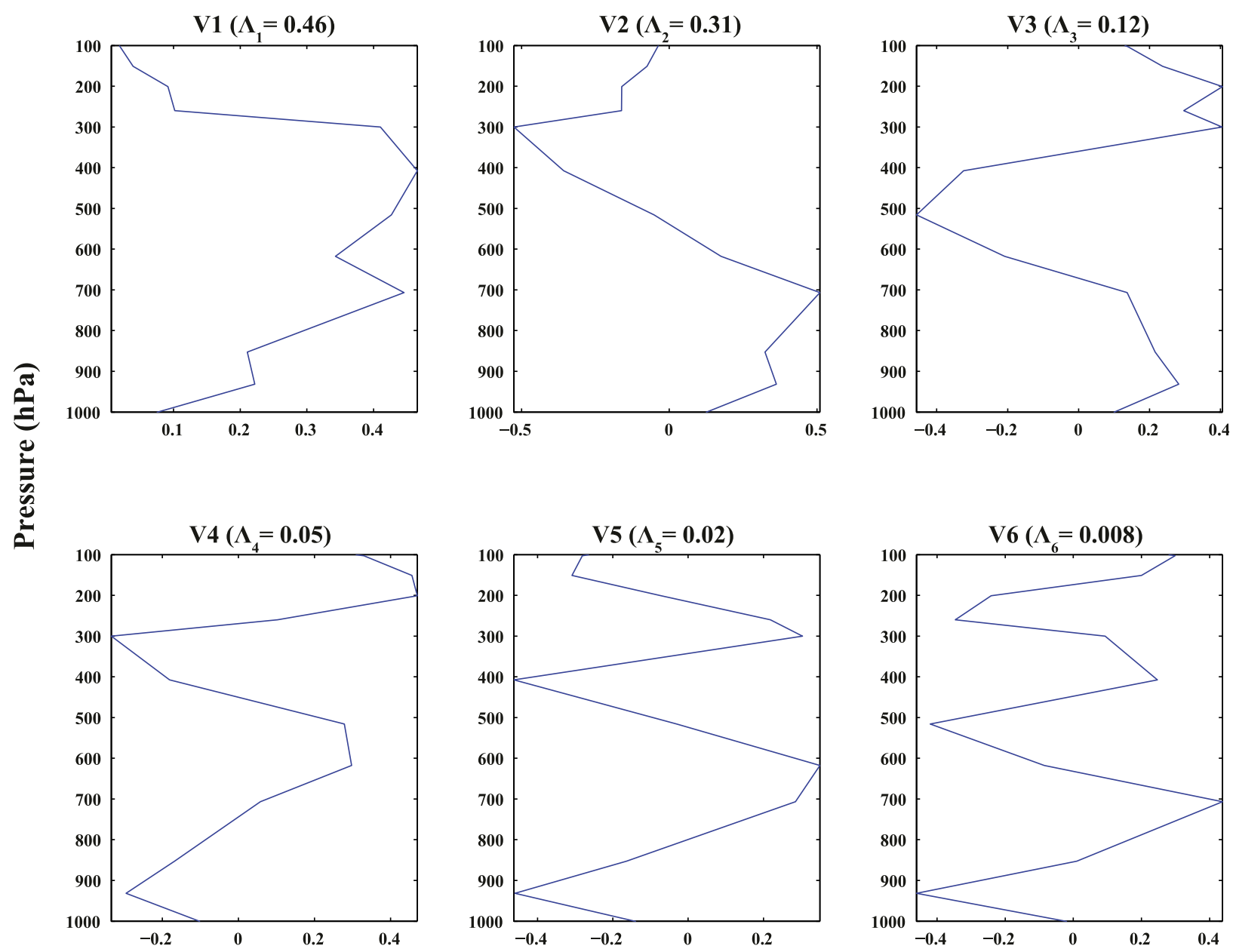

FIG. A2. The first six components of right singular vectors from the SVD of globally averaged RH radiative kernels, with their corresponding eigenvalues indicated.

true values as a function of $\lambda$. In this paper, the $\mathbf{K}$ is the spectral $\mathrm{RH}$ radiative kernel that relates the TOA flux change $\mathbf{y}$ to the change of RH profile $\mathbf{x}$.

Another method is the truncated singular value decomposition (SVD) method (Hansen 1990). In SVD decomposition, we express the RH Jacobian $\mathbf{K}$ in the form

$$
\mathbf{K}=\mathbf{U} \mathbf{\Lambda} \mathbf{V}^{\mathrm{T}}
$$

where $\boldsymbol{\Lambda}$ is the diagonal matrix of singular values and $\mathbf{U}$ and $\mathbf{V}$ are orthogonal matrices of its left and right singular vectors. Using this eigenvector basis, the $\mathbf{K}^{-1}$ can be approximately by

$$
\mathbf{K}^{-1}=\mathbf{V}_{t} \mathbf{\Lambda}_{t}^{-1} \mathbf{U}_{t},
$$

where the subscript $t$ means that only the $t$ largest eigenvalues and their corresponding eigenvectors are remained. The dropped eigenvalues and eigenvectors would greatly contribute to error terms. The term $\mathbf{K}^{-1}$ can relate the RH spectral feedbacks to profiles of $\mathrm{RH}$ changes by multiplying $\mathbf{K}^{-1}$ with $\mathrm{RH}$ spectral feedbacks and surface temperature change. Figures A1 and A2 show the first six left singular vectors in $\mathbf{U}$ and right singular vectors in $\mathbf{V}$ when their corresponding eigenvalues are in descending order. From the first singular vector in $\mathbf{U}$ and $\mathbf{V}$, negative $\mathrm{RH}$ changes through the whole troposphere can be inferred from negative radiation changes across the whole spectrum when contributions in the far-IR $\left(60-600 \mathrm{~cm}^{-1}\right)$ and window regions $\left(800-1200 \mathrm{~cm}^{-1}\right)$ are comparable to each other. From the second singular vector in $\mathbf{U}$ and $\mathbf{V}$, an increase of $\mathrm{RH}$ in the lower troposphere can be inferred from positive radiation changes in the far IR, while a decrease in uppertroposphere $\mathrm{RH}$ can be inferred from negative radiation changes in window regions. For the inversion in this paper, we use first five singular vectors as well as eigenvalues in the high latitudes and six in the other regions. 

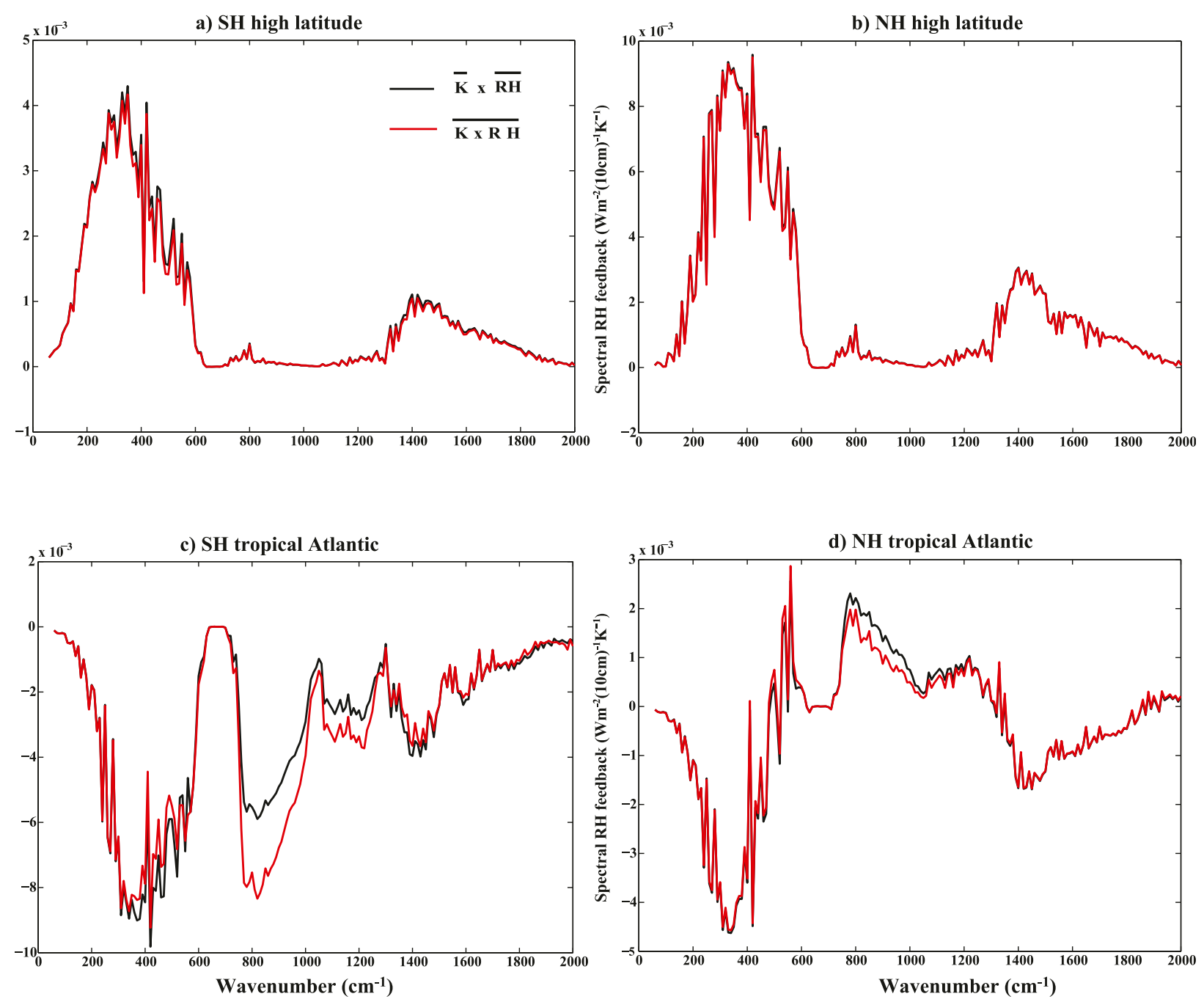

e) Deep tropical Pacific

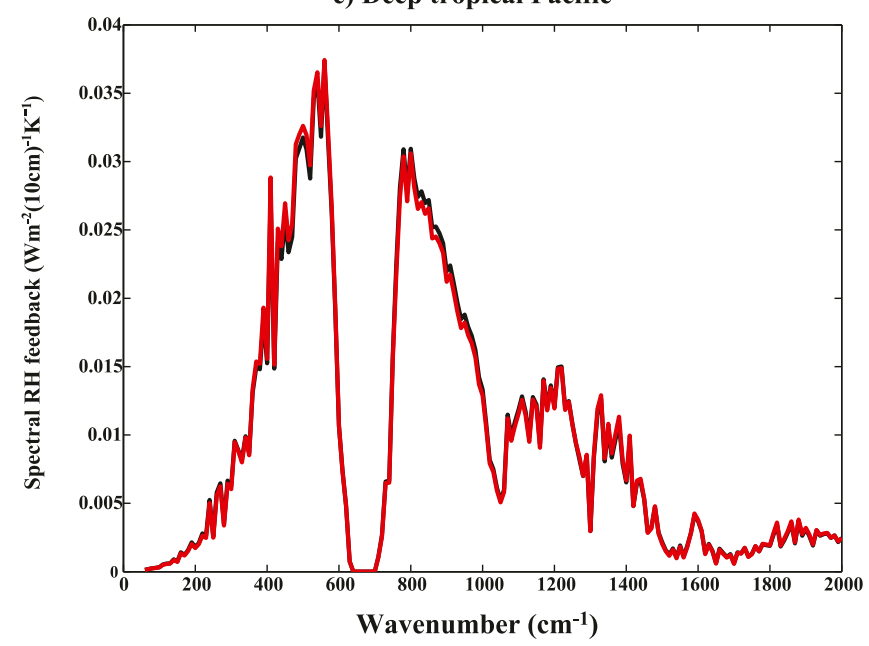

FIG. B1. The spatial average of TOA radiance changes due to RH perturbations, i.e., $\overline{\mathbf{K} \times \Delta \mathbf{R H}}$ and $\overline{\mathbf{K}} \times \overline{\Delta \mathbf{R H}}$, in the (a) high latitudes in the Southern Hemisphere $\left(60^{\circ}-90^{\circ} \mathrm{S}\right)$, (b) high latitudes in the Northern Hemisphere $\left(60^{\circ}-90^{\circ} \mathrm{N}\right)$, (c) the tropical Atlantic in the Southern Hemisphere $\left(5^{\circ}-20^{\circ} \mathrm{S}, 300^{\circ}-350^{\circ} \mathrm{E}\right)$, (d) the tropical Atlantic in the Northern Hemisphere $\left(5^{\circ}-20^{\circ} \mathrm{N}, 300^{\circ}-350^{\circ} \mathrm{E}\right)$, and (e) the deep tropical Pacific $\left(5^{\circ} \mathrm{S}-5^{\circ} \mathrm{N}, 200^{\circ}-250^{\circ} \mathrm{E}\right)$. 

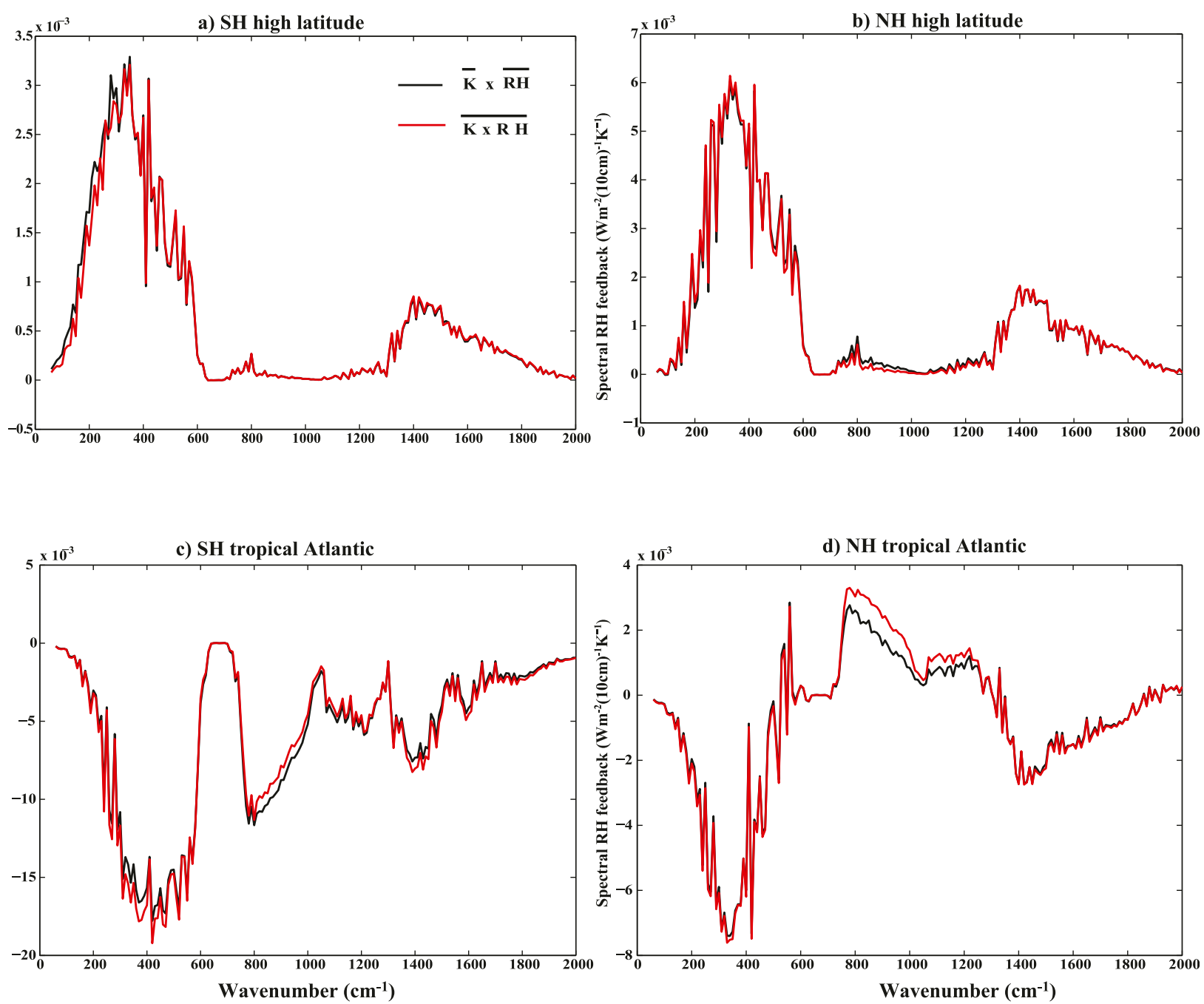

e) Deep tropical Pacific

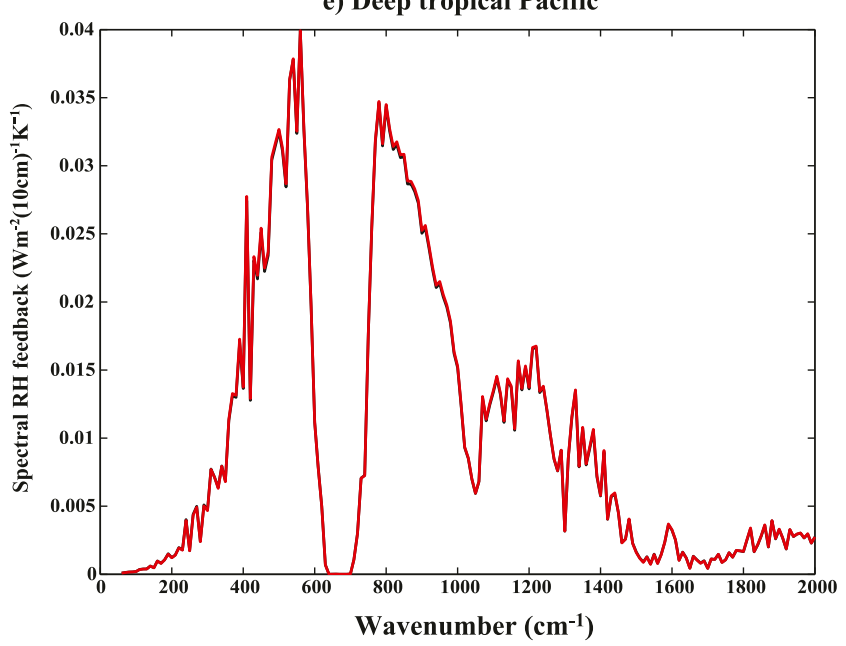

FIG. B2. The temporal average of TOA radiance changes due to RH perturbations, i.e., $\overline{\mathbf{K} \times \Delta \mathbf{R H}}$ and $\overline{\mathbf{K}} \times \overline{\Delta \mathbf{R H}}$, in the five regions explained in Fig. B1. 


\section{APPENDIX B}

\section{An Assumption in Retrieving the Average Changes of RH Profiles from the Average Changes of TOA Fluxes}

In section $3 b$ we try to retrieve the regional 20-yr aver-

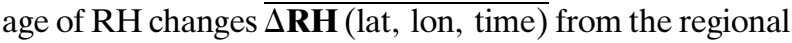
average of TOA flux changes $\overline{\Delta \mathbf{R} \text { (lat, lon, time) }}$ due to the RH perturbations. (An overbar represents averaging over all variables in the parentheses.) The retrieval is performed through the inversion of regional average of

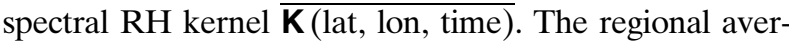
age of TOA flux changes $\overline{\Delta \mathbf{R} \text { (lat, lon, time) }}$ is obtained in two steps: first we multiply the RH kernel $\mathbf{K}$ (lat, lon, time) by the RH perturbation $\Delta \mathbf{R H}$ (lat, lon, time) to get the TOA flux changes $\Delta \mathbf{R}$ (lat, lon, time) on each grid box (lat, lon) for every month (time) in 20 years; second we spatially and temporally average $\Delta \mathbf{R}$ (lat, lon, time)

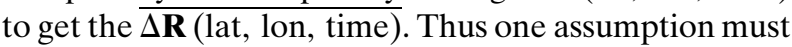
be valid before the retrieval:

$$
\overline{\Delta \mathbf{R}}=\overline{\mathbf{K} \times \Delta \mathbf{R H}} \cong \overline{\mathbf{K}} \times \overline{\Delta \mathbf{R H}} .
$$

The two left sides are the average TOA flux changes $\overline{\Delta \mathbf{R} \text { (lat, lon, time) }}$ on which we would perform inversion, and $\overline{\Delta \mathbf{R H}}$ on the right side is the average change of $\mathrm{RH}$ profiles that we would like to obtain. The assumption for retrievals is that the order of multiplying and averaging would affect little the ultimate results. The averages of TOA flux changes due to RH perturbations for a given geographical region are well approximated by the product of the average of spectral RH kernels and the average of RH perturbations over the same region.

To test the assumption, we perform the following experiments based on the RH output from GFDL CM3 in each of the five regions in section 3b. First, we test whether Eq. (B1) is valid for spatial average. We calculate the annual mean perturbations of $\mathrm{RH}$ profiles $\Delta \mathbf{R H}($ lat, lon) in one year and the annual mean spectral RH kernel K(lat, lon) on each grid box. Then we

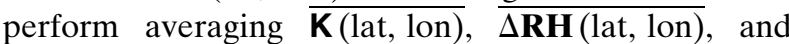
$\overline{\mathbf{K}}$ (lat, lon) $\Delta \mathbf{R H}$ (lat, lon) over all grid boxes in the chosen region. Second, we test whether Eq. (B1) is valid for the temporal average in a similar way. We calculate the monthly regional average of perturbations of $\mathrm{RH}$ profiles in one year $\Delta \mathbf{R H}($ mon) and the monthly regional average of spectral RH kernel $\mathbf{K}(\mathrm{mon})$. Then we calculate the annual mean $\overline{\mathbf{K}(\mathrm{mon})}, \overline{\Delta \mathbf{R H}(\mathrm{mon})}$, and $\overline{\mathbf{K}(\text { mon }) \Delta \mathbf{R H}(\mathrm{mon})}$ over the 12 months. The average TOA flux changes due to RH perturbations in two calculation orders, that is, $\overline{\mathbf{K} \times \Delta \mathbf{R H}}$ (first multiply $\mathbf{K}$ and $\Delta \mathbf{R H}$ and then average) and $\overline{\mathbf{K}} \times \overline{\Delta \mathbf{R H}}$ (first average $\mathbf{K}$ and $\Delta \mathbf{R H}$ and then multiply) for spatial average and temporal average, are separately shown in Figs. B1 and B2 in the five regions. Over the tropical Pacific Ocean, whatever the operation order, the two lines almost overlap each other. In the high latitudes on both hemispheres, to a large degree, Eq. (B1) is valid. However, over the tropical Atlantic Ocean, the operation order matters. The average TOA flux changes by $\overline{\mathbf{K} \times \Delta \mathbf{R H}}$ and $\overline{\mathbf{K}} \times \overline{\Delta \mathbf{R H}}$ are not consistent with each other, which means that our retrieved regional average of $\mathrm{RH}$ changes are probably deviated from the true changes.

\section{REFERENCES}

Allen, M. R., and W. J. Ingram, 2002: Constraints on future changes in climate and the hydrologic cycle. Nature, 419, 224-232, https://doi.org/10.1038/nature01092.

Anderson, J. L., and Coauthors, 2004: The new GFDL global atmosphere and land model AM2-LM2: Evaluation with prescribed SST simulations. J. Climate, 17, 4641-4673, https://doi.org/ 10.1175/JCLI-3223.1.

Brindley, H. E., and R. J. Bantges, 2016: The spectral signature of recent climate change. Curr. Climate Change, 2, 112-126, https://doi.org/10.1007/s40641-016-0039-5.

Caldwell, P. M., and Coauthors, 2016: Quantifying the sources of intermodel spread in equilibrium climate sensitivity. J. Climate, 29, 513-524, https://doi.org/10.1175/JCLI-D-15-0352.1.

Chahine, M. T., and Coauthors, 2006: AIRS: Improving weather forecasting and providing new data on greenhouse gases. Bull. Amer. Meteor. Soc., 87, 911-926, https://doi.org/10.1175/ BAMS-87-7-911.

Chen, X., X. Huang, N. G. Loeb, and H. Wei, 2013: Comparisons of clear-sky outgoing far-IR flux inferred from satellite observations and computed from the three most recent reanalysis products. J. Climate, 26, 478-494, https://doi.org/10.1175/JCLI-D-12-00212.1.

Colman, R., and B. J. McAvaney, 1997: A study of general circulation model climate feedbacks determined from perturbed SST experiments. J. Geophys. Res., 102, 19383-19 402, https:// doi.org/10.1029/97JD00206.

Han, Y., and Coauthors, 2013: Suomi NPP CrIS measurements, sensor data record algorithm, calibration and validation activities, and record data quality. J. Geophys. Res., 118, 12734 12 748, https://doi.org/10.1002/2013JD020344.

Hansen, P. C., 1990: Truncated singular value decomposition solutions to discrete ill-posed problems with ill-determined numerical rank. SIAM J. Sci. Stat. Comput., 11, 503-518, https:// doi.org/10.1137/0911028.

Harries, J. E., E. Brindley, P. J. Sagoo, and R. J. Bantges, 2001: Increases in greenhouse forcing inferred from the outgoing longwave radiation spectra of the Earth in 1970 and 1997. Nature, 410, 355-357, https://doi.org/10.1038/35066553.

Held, I. M., and B. J. Soden, 2000: Water vapor feedback and global warming. Annu. Rev. Energy Environ., 25, 441-475, https:// doi.org/10.1146/annurev.energy.25.1.441.

— , and K. M. Shell, 2012: Using relative humidity as a state variable in climate feedback analysis. J. Climate, 25, 25782582, https://doi.org/10.1175/JCLI-D-11-00721.1.

Hilton, F., and Coauthors, 2012: Hyperspectral Earth observation from IASI: Five years of accomplishments. Bull. Amer. Meteor. Soc., 93, 347-370, https://doi.org/10.1175/ BAMS-D-11-00027.1. 
Huang, X. L., V. Ramaswamy, and M. D. Schwarzkopf, 2006: Quantification of the source of errors in AM2 simulated tropical clear-sky outgoing longwave radiation. J. Geophys. Res., 111, D14107, https://doi.org/10.1029/2005JD006576.

$\longrightarrow$, X. H. Chen, B. J. Soden, and X. Liu, 2014: The spectral dimension of longwave feedback in the CMIP3 and CMIP5 experiments. Geophys. Res. Lett., 41, 7830-7837, https:// doi.org/10.1002/2014GL061938.

Huang, Y., and V. Ramaswamy, 2008: Observed and simulated seasonal co-variations of outgoing longwave radiation spectrum and surface temperature. Geophys. Res. Lett., 35, L17803, https://doi.org/10.1029/2008GL034859.

,,-- X. L. Huang, Q. Fu, and C. Bardeen, 2007: A strict test in climate modeling with spectrally resolved radiances: GCM simulation versus AIRS observations. Geophys. Res. Lett., 34, L24707, https://doi.org/10.1029/2007GL031409.

— S. Leroy, P. J. Gero, J. Dykema, and J. Anderson, 2010a: Separation of longwave climate feedbacks from spectral observations. J. Geophys. Res., 115, D07104, https://doi.org/ 10.1029/2009JD012766.

$\longrightarrow,-$, and J. G. Anderson, 2010b: Determining longwave forcing and feedback using infrared spectra and GNSS radio occultation. J. Climate, 23, 6027-6035, https://doi.org/10.1175/ 2010JCLI3588.1.

Ingram, W. J., 2002: On the robustness of the water vapor feedback, GCM vertical resolution and formulation. J. Climate, 15, 917-921, https://doi.org/10.1175/1520-0442(2002)015<0917: OTROTW $>2.0 . \mathrm{CO} ; 2$.

Kato, S., F. G. Rose, X. Liu, B. A. Wielicki, and M. G. Mlynczak, 2014: Retrieval of atmospheric and cloud property anomalies and their trend from temporally and spatially averaged infrared spectra observed from space. J. Climate, 27, 4403-4420, https://doi.org/10.1175/JCLI-D-13-00566.1.

Liu, X., W. L. Smith, D. K. Zhou, and A. Larar, 2006: Principal component-based radiative transfer model for hyperspectral sensors: Theoretical concept. Appl. Opt., 45, 201-209, https:// doi.org/10.1364/AO.45.000201.

Pierrehumbert, R. T., H. Brogniez, and R. Roca, 2007: On the relative humidity of the Earth's atmosphere. The Global Circulation of the Atmosphere, T. Schneider and A. H. Sobel, Eds., Princeton University Press, 143-185.

Shell, K. M., J. T. Kiehl, and C. A. Shields, 2008: Using the radiative kernel technique to calculate climate feedbacks in NCAR's Community Atmospheric Model. J. Climate, 21, 2269-2282, https://doi.org/10.1175/2007JCLI2044.1.

Sherwood, S. C., W. Ingram, Y. Tsushima, M. Satoh, M. Roberts, P. L. Vidale, and P. A. O'Gorman, 2010: Relative humidity changes in a warmer climate. J. Geophys. Res., 115, D09104, https://doi.org/10.1029/2009JD012585.

Soden, B. J., and I. M. Held, 2006: An assessment of climate feedbacks in coupled ocean-atmosphere models. J. Climate, 19, 3354-3360, https://doi.org/10.1175/JCLI3799.1.

,-- , R. Colman, K. M. Shell, J. T. Kiehl, and C. A. Shields, 2008: Quantifying climate feedbacks using radiative kernels. J. Climate, 21, 3504-3520, https://doi.org/10.1175/2007JCLI2110.1.

Taylor, K. E., R. J. Stouffer, and G. A. Meehl, 2012: An overview of CMIP5 and the experiment design. Bull. Amer. Meteor. Soc., 93, 485-498, https://doi.org/10.1175/BAMS-D-11-00094.1.

Trenberth, K. E., J. Fasullo, and L. Smith, 2005: Trends and variability in column-integrated atmospheric water vapor. Climate Dyn., 24, 741-758, https://doi.org/10.1007/s00382-005-0017-4.

Twomey, S., 1977: Introduction to the Mathematic of Inversion in Remote Sensing and Indirect Measurements. Elsevier Scientific, $242 \mathrm{pp}$.

Wentz, F. J., and M. Schabel, 2000: Precise climate monitoring using complementary satellite data sets. Nature, $\mathbf{4 0 3}, 414-416$, https://doi.org/10.1038/35000184.

_ L. Ricciardulli, K. Hilburn, and C. Mears, 2007: How much more rain will global warming bring? Science, 317, 233-235, https://doi.org/10.1126/science.1140746. 